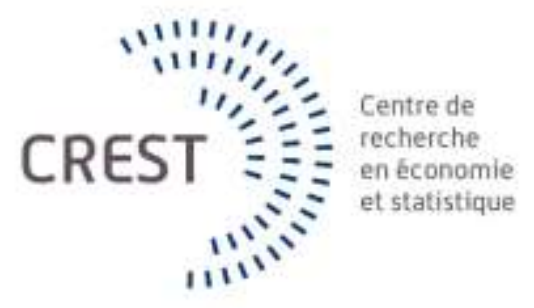

Série des Documents de Travail

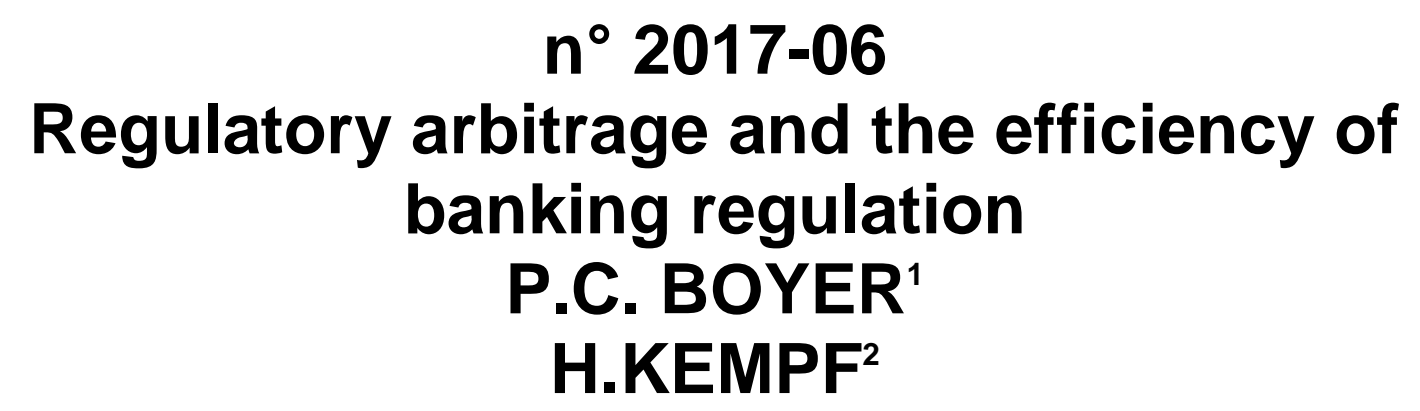

Les documents de travail ne reflètent pas la position du CREST et n'engagent que leurs auteurs. Working papers do not reflect the position of CREST but only the views of the authors.

\footnotetext{
${ }^{1}$ CREST, École Polytechnique, Université Paris-Saclay. E-mail : pierre.boyer@polytechnique.edu

${ }^{2}$ CREST, École Normale Supérieure Paris-Saclay. E-mail : hubert.kempf@ens-cachan.fr
} 


\title{
Regulatory arbitrage and the efficiency of banking regulation*
}

\author{
Pierre C. Boyer ${ }^{\dagger}$ and Hubert Kempf ${ }^{\ddagger}$
}

August 10, 2017

\begin{abstract}
We study the efficiency of banking regulation under financial integration. Banks freely choose the jurisdiction where to locate their activities and have private information about their efficiency level. Regulators non-cooperatively offer any regulatory contract that satisfies information and participation constraints of banks. We show that the unique Nash equilibrium of the regulatory game is a simple pooling contract: financial integration is characterized by the inability for regulators to discriminate between banks with different efficiency levels. This result is driven by the endogenous restriction caused by regulatory arbitrage on the capacity of regulators to use several regulatory instruments.

Keywords: Regulatory Arbitrage; Banking regulation; Regulatory competition; Financial integration; Asymmetric information.

JEL classification: C72; D82; G21; G28.
\end{abstract}

${ }^{*}$ We thank Tobias Berg, Frédéric Boissay, Gunther Capelle-Blancard, Cécile Casteuble, Jean-Edouard Colliard, Jézabel Couppey-Soubeyran, Hans Peter Grüner, Andreas Haufler, Martin Hellwig, Steven Ongena, Bruno Parigi, Jorge Ponce, Jean-Charles Rochet, Eva Schliephake, Pierre-Olivier Weill, and Lucy White for very helpful comments, as well as seminar participants at the University of Zurich, Banque de France, Mannheim University, Max Planck Institute in Bonn, ESCP Europe-Paris 1, CESifo Area Conference on Applied Microeconomics 2016 in Munich, EEA-ESEM 2016 in Geneva, and AFSE 2016 in Nancy. The authors gratefully acknowledge the Europlace Institute of Finance and the Investissements d'Avenir (ANR-11-IDEX-0003/Labex Ecodec/ANR-11-LABX-0047) for financial support.

${ }^{\dagger}$ CREST, École Polytechnique, Université Paris-Saclay, Route de Saclay, 91128 Palaiseau, France. E-mail: pierre.boyer@polytechnique.edu

${ }^{\ddagger}$ École Normale Supérieure Paris-Saclay, Avenue du président Wilson, 94235 Cachan cedex and CREST. E-mail: hubert.kempf@ens-cachan.fr (Corresponding author) 


\section{Introduction}

It is common to consider that international financial integration weakens the efficiency of banking regulation as national regulatory authorities are involved in a "race to the bottom", leading them to relax their requirements compared to those which would be set if their economy were closed. ${ }^{1}$ The present paper goes beyond this view: we claim that what is involved is not so much a weakening of regulatory standards as the inability to efficiently regulate the risk-taking by banks when they are freely able to direct their investment flows worldwide.

The financial opening process under way since the mid-eighties has led many economists and policymakers to worry about the necessity to regulate the ever-increasing crosscountry financial flows. In the aftermath of the worldwide banking crisis following the collapse of Lehman Brothers in 2008 many proposals to implement new regulatory tools have been made. ${ }^{2}$ In particular regulations in relation with the appropriate level of risktaking activities of banks attract a lot of attention and debates. ${ }^{3}$ But a preliminary issue has first to be answered: are banking regulation institutions in capacity of efficiently regulating financial flows in a financially integrated economy? This requires that these public authorities do control a sufficiently large set of regulatory instruments. Is it so in a financially integrated economy?

Financial integration creates de facto competition between national regulatory jurisdictions. In this environment, a usual concern of policy-makers when imposing tougher regulatory standards than other countries is the revenue loss from the location of the financial activities out of their jurisdiction: the banks are able to locate their activity according to the most favorable regulations and regulatory arbitrage has to be taken into account when implementing (new) regulations. ${ }^{4}$ Focusing on liquidity regulation tools, we prove that the competition induced by regulatory arbitrage in a financially open economy invalidates the use of some instruments and consequently critically hampers the regulatory capacity of these authorities.

To make these points, this paper develops an original framework based on a mech-

\footnotetext{
${ }^{1}$ See, for instance, Acharya (2003), Dell'Ariccia and Marquez (2006), Barth et al. (2006), Morrison and White (2009), Schepens (2016), and Carruthers and Lamoreaux (2016).

${ }^{2}$ See for proposals and reviews Claessens et al. (2010), de Mooij and Nicodème (2014), and Benoit et al. (2017).

${ }^{3}$ See Admati et al. (2011), Admati and Hellwig (2014), Bolton and Freixas (2006), Bolton et al. (2011), Cochrane (2014), Hart and Zingales (2011), Miles et al. (2013), among others.

${ }^{4}$ Several empirical studies find evidence of regulatory arbitrage (see, for instance, Dong et al. (2011), Aiyar et al. (2012), Carbo-Valverde et al. (2012), Houston et al. (2012), Ongena et al. (2013), Agarwal et al. (2014), Karolyi and Taboada (2015), and Reinhardt and Sowerbutts (2015)).
} 
anism design approach to provide theoretical grounds for the feasibility of regulatory instruments. This approach is the dominant paradigm in regulatory economics as it grounds the constraints faced by regulators on firm microeconomic foundations. ${ }^{5}$ Our methodological contribution is to apply this paradigm on the issue of banking regulatory competition. Two set of constraints have to be considered: first, banks can have different levels of efficiency in managing their investment portfolio, and their efficiency is their private information with respect to the regulators. This is a traditional friction that puts regulators at an informational disadvantage. ${ }^{6}$ This informational gap that has to be taken into account when designing their regulations (formally, the regulatory contracts) leads to the imposition of information constraints. Second, the assumption of voluntary participation of banks to the economy leads to the imposition of participation constraints. These two set of constraints describe the set of allocations that the regulators can achieve despite their lack of information. On a general level, an allocation is an output that is reached and a distribution of the gains from trade. In our environment, an output is a chosen risk-related asset portfolio and the distribution of the gains from trade that comes from the repartition of the profits generated from risky investments. We show that the regulatory instruments used in an optimal regulatory allocation are twofold: a liquidity requirement that regulates the riskiness of banks' portfolio and a tax levied to control the overall profit of banks. Any alternative pair of instruments could be considered insofar as these instruments simultaneously affect the degree of the riskiness of banks' portfolio and regulate the overall profit of banks. An important property of the optimal regulatory contracts offered to banks is that they are efficiency-contingent. This result is consistent with the traditional regulatory literature on discriminatory regulatory schemes: banks with different efficiency levels in risk management are subject to regulatory contracts that allow more efficient banks to have a riskier portfolio.

A key tension on the implementation of regulatory contracts comes from regulatory arbitrage: a bank can choose between the contracts proposed by the regulators. In the sequel we refer to this choice as the location choice of a bank. The capacity of banks to choose their regulatory contracts captures the idea that the world economy is financially integrated and banks have the capacity to freely decide on financial flows. In real life it may be through the use of subsidiaries in foreign countries or different jurisdictions. A subsidiary is regulated according to its jurisdiction's law. A bank may be legally attached to a country and its headquarters may be located in this country, but the possibility to

\footnotetext{
${ }^{5}$ See, e.g., Laffont and Tirole (1993), and Giammarino et al. (1993) for an early application of this framework to better understand solvency issues.

${ }^{6}$ See Dewatripont and Tirole (1994), Laffont and Tirole (1993), and Freixas and Rochet (2008). See also Laffont and Martimort (2002) and Bolton and Dewatripont (2008) for contract theory references.
} 
open subsidiaries elsewhere and freely move funds for investment between the founding entity and its subsidiaries amounts to let banks choose among several regulatory options. This put regulators under competitive pressure: by making the terms of the regulatory contract more favorable to banks, a local authority may hope to attract more banks' activities in its jurisdiction. ${ }^{7}$

Our main result shows that regulatory arbitrage leads to a simple pooling regulatory contract as the unique Nash equilibrium of the regulatory game. This implies that the internationalization of banks annihilates the capacity of national public authorities in charge of banks' regulation to use the proper set of regulatory instruments.

The pooling regulatory contract has two important features. First, it treats all banks alike independently of their efficiency levels. Hence, our model predicts that banking regulation does not lead to sophisticated discrimination between the banks since all banks are going to be subject to the same rule. Second, within the set of allocations that are incentive compatible and satisfy participation constraints, the regulatory equilibrium pins down an allocation that is inefficient in term of risk-taking investment and where no redistribution of gains from investment occurs. Such equilibrium is obtained because one of the instruments that is in the set of regulatory tools cannot be sustained and used by the regulators in a Nash equilibrium when banks are mobile: no tax is levied on banks' profits. Any attempts to use additional instruments to attract banks would be redundant and attracting the most efficient banks only is not a profitable deviation from the pooling contract.

Our main finding builds on the following intuition: banks are sensitive to after-tax profits and profits depend both on the tax level and the amount of risky investment allowed by the regulators. The possibility for banks to choose their location puts noncooperating regulators in conflict. The national regulator views a decrease in the contractual tax level as an opportunity for increasing the residents' welfare: by diminishing the tax level levied on each bank in her jurisdiction, the regulator balances the loss of revenues per bank with an increase of the total amount of taxes collected by attracting many more banks to her jurisdiction. On the other hand she minds exposing her residents to too high levels of risk-taking by banks. Off equilibrium a small variation in the tax level is isolated from the liquidity regulation, which regulates the risk taking behavior of banks. However the logic of undercutting taxes leads to an aggressive underbidding

\footnotetext{
${ }^{7}$ This incentive is present even when the regulators focus on consumers' welfare and do not take into account on the profits of banks in their objective: consumers benefit from having banks located in their jurisdiction. In the core of our analysis we derive our results under the assumption that regulators put some weight only on consumers' welfare. We show in Section 7 that our main results hold if regulators attached some weight to banks' profit on top of the welfare of consumers.
} 
which eventually forces both regulators to drive down their taxes to zero. The important implication of this result is that the mobility of banks leads to the loss of one regulatory instrument. Left with solely liquidity requirement in their toolbox, the regulatory contracts offered by non-cooperating regulators can no longer discriminate between banks of different efficiency levels. In brief, in an incomplete information environment where banks can choose to locate their activities under the most favorable regulation, our main result implies that the regulatory non-cooperative equilibrium generates a unique liquidity requirement, defining the extent of risk being taken by banks, valid for all banks independently of their efficiency levels. Thus the banking regulation is inefficient insofar that it is unable to discriminate among diversely efficient banks.

Our result raises the issue of the benefits of integrating the regulatory design at a (hypothetical) supranational level. In our model, focusing on the mobility capacity of banks, we prove that such an integration restores the capacity to discriminate among banks. In other words, the transfer of the regulatory task to a supranational authority counters the capacity of banks to benefit from regulatory arbitrage. However, contrarily to the intuition, when we compare the regulatory outcome under integrated versus competing regulators, we prove that regulatory arbitrage does not necessarily lead to a race to the bottom in regulatory standards: the aggregate level of risks taken by banks can be higher under the optimal efficiency-specific regulatory contracts than under the pooling contract resulting from competing regulators.

In the core of our analysis, banks are granted monopoly power on resident depositors. An important aspect of financial integration is the improvement of services that consumers may enjoy from the increase of competition in the banking sector. To take this effect into account we extend our analysis to the case where banks compete for deposits instead of being granted monopoly power on resident depositors. Such competition forces banks to improve the terms of their deposit contracts so as to attract or retain customers. We show that our main result is qualitatively unchanged when competition for deposits is taken into account: we still obtain a pooling contract as the unique Nash equilibrium, for the same reason as stated above, the loss of a regulatory instrument (no taxes are raised in equilibrium). An interesting insight from this extension is that because households have a higher interest in the risky investment through the competition between banks, this reduces the effectiveness of taxation as a regulatory instrument even when we abstract from regulatory competition. Therefore it becomes more difficult to use taxation so as to screen banks according to their efficiency levels.

The rest of the paper is organized as follows. In the following section we present the 
related literature. Section 3 introduces the two-country model. As a benchmark, Section 4 shows the characteristics of the optimal regulatory contracts in our environment. Section 5 gathers our main results when banks can choose their regulator; in particular it presents the Nash equilibrium regulatory contract and its characteristics. We contrast this case with the case of integrated regulation in Section 6. In Section 7 we clarify how alternative modeling choices would affect our results. In particular, we show how our results extend if we allow for more than two countries or a more general structure of shocks affecting the portfolio of banks, and if regulators attached some weight to banks' profit on top of the welfare of consumers. We also show how imperfect mobility of banks and introducing many dimensions of heterogeneity between banks affect our results. We extend our model in Section 8 where we account for the possibility that financial integration increase banks' competition for deposits. The last section contains concluding remarks. All the proofs are relegated to the Appendix.

\section{Related literature}

Our contribution builds a bridge between the literature on optimal regulation and the literature on regulatory arbitrage in the banking sector. ${ }^{8}$ The new regulatory economics literature has made important contributions to our understanding of optimal design of the regulatory contracts for firms without making ad hoc restrictions on the regulatory scheme (see Laffont and Tirole (1993) for a review). These contracts give insights not only on the optimal set of instruments necessary to regulate firms but also on the design of optimal institutions. However, this literature has not considered the regulation of banks in an open economy where banks can decide where to locate their investments. ${ }^{9}$

The theoretical foundations of financial regulation have been clarified by Allen and Gale (2004). They prove that such a public intervention is desirable when markets are incomplete, not solely because financial markets are incomplete. In this respect financial regulation is similar to any public intervention: it may be justified by the presence of some market failure.

White (1994) is an early attempt to address the issue of banking regulation in an internationally open environment: drawing a parallel with industrial economics, he claims that international cooperation among regulators may not be sustainable. Vives (2001)

\footnotetext{
${ }^{8}$ Our methodology is related to the public finance literature that studies competitions over nonlinear income taxes, see e.g. Morelli et al. (2012), Bierbrauer et al. (2013), Lehmann et al. (2014), and Bierbrauer and Boyer (2016).

${ }^{9}$ Boyer and Ponce (2012) is an example of optimal banking regulation and supervision in a closed economy.
} 
discusses the impact of European monetary integration on financial regulation in Europe. Dell'Ariccia and Marquez (2006)'s focus is similar to ours. They study a two-country economy where national authorities regulate the lending activity of banks under their control. Regulators may or may not cooperate in setting their regulatory instrument. Competition between banks comes from the fact that they can lend to borrowers in both countries. This is an alternative way to model the international mobility of banks. They find a race to the bottom as regulators choose lower requirements than the one that would be chosen by a centralized regulator. ${ }^{10}$ The critical difference with our own setting is that they assume that the regulator controls a unique instrument, capital requirement, as a buffer against project failure.

The absence of an optimal regulatory set-up aimed at solving an informational asymmetry between regulators and banks is also a feature of the study by Engineer et al. (2013). They investigate a regulatory competition between national regulators the object of which is deposit insurance. Here the international mobility in banking comes from the fact that depositors themselves are able to choose the bank where they deposit. They find a "race to the top" characteristics as national authorities aim at attracting more depositors by raising the deposit insurance ceiling, which amounts to a suboptimal equilibrium.

The Basel Committee on Banking remains committed to the principle of a level playing field in banking regulation in order to allow banks and financial institutions to be subject to the same regulatory setting and thus make competition between banks more open and efficient. ${ }^{11}$ Acharya (2003) proves that a level playing field can result in a regulatory race to the bottom but he does not consider an optimal regulatory set-up. Morrison and White (2009) uncover another trade-off related to this issue. They prove that the objective of a level playing field amounts to imposing the weakest standards, i.e. accepts the race to the bottom. It harms the countries with high quality regulators (with a high reputation) and benefits to banks in weaker economies by countering a "cherry-picking externality." In their setting, the public authority is both a regulator, assigning banking licenses, and a supervisor, able to control the efficiency of banks. Banks offer incentive-compatible contracts to their clients, but not national regulators. When the banking sector is internationally open, banks compete for licences and thus for the efficiency of national authority. The obtention of a licence from one authority affects a

\footnotetext{
${ }^{10}$ This is reminiscent of the race to the bottom in international tax competition. See the recent survey by Keen and Konrad (2013). See, however, Haufler and Maier (2016) who find that regulatory competition in capital standards can lead to a race to the top when banks differ exogenously in the quality of their monitoring, and hence in the likelihood that their loans will succeed.

${ }^{11}$ See Morrison and White (2009) for references.
} 
bank's capacity to attract deposits (external financing) and thus its size: better regulated banks attract more deposits and are of a larger size. This is the "cherry-picking effect". A level playing field makes banks equally attractive in any country and thus of the same size.

Finally, our framework shares some aspects with the one used to study competition between profit-maximizing firms that offer nonlinear price schedules like in competitive insurance markets. ${ }^{12}$ In particular, our main result showing that regulatory arbitrage leads to a simple pooling regulatory contract is reminiscent to the difficulty of sustaining a separating equilibrium in competitive insurance markets. ${ }^{13}$

To sum up, the analysis of an international banking sector combining an optimal regulatory set-up aimed at solving informational asymmetries and competition between national regulators which do not cooperate has not yet been addressed. This paper represents a first step in that direction.

\section{A two-country model}

\subsection{The environment}

We consider a three-period economy with three types of agents: regulators, banks, and households. All agents have a discount factor equal to 1. For simplicity, we assume that there are two countries (jurisdictions), indexed by $j=1,2$. We show in Section 7 that our results also hold with more than two countries.

Households. In each country, there is a representative household living for three periods. She is endowed with $D$ units of money in period 0 . She consumes in periods 1 and 2 and thus wants to make intertemporal transfers. Her utility function is written as

$$
U\left(c_{j 1}\right)+U\left(c_{j 2}\right),
$$

where $c_{j i}$ represents the consumption level in period $i=1,2$ of the representative household living in $j=1,2$. We assume that the utility function $U(\cdot)$ is twice continuously differentiable with $U^{\prime}(\cdot)>0>U^{\prime \prime}(\cdot)$, and satisfies Inada conditions: $U^{\prime}(0)=+\infty$ and $U^{\prime}(+\infty)=0$. She has no direct access to intertemporal transfer technology and thus

\footnotetext{
${ }^{12}$ These papers belong to a larger literature on competing mechanisms; see Martimort (2006) for a survey.

${ }^{13}$ See Attar et al. (2014) for an extensive discussion on cream-skimming issues.
} 
uses a bank for this purpose: ${ }^{14}$ her bank deposit is $D$ and the bank offers her a contract specifying the available sum in period 1 and 2 .

Banks. There is one representative bank in each country and consumers are assigned to its representative bank. Hence households have a passive role and there is no competition between banks for deposits. ${ }^{15}$ The gross interest rate on the deposits is normalized to 1 .

Each bank has access to two financial assets: a safe and a risky one. The safe asset is available in any period without costs. This is a liquid asset and it can be thought as holding cash reserves. The risky asset has a maturity of two periods and thus is available only in period 0. After the investment decision has been made a (macro) shock occurs in the two countries such that with probability $1-\rho$ all illiquid assets have to be liquidated - one can think of this shock as a global financial crisis. ${ }^{16}$ For a bank of type $\theta$, if this asset is not liquidated in period 1 it delivers a return of $\theta R$ in period 2 for 1 unit invested in period 0 . If this asset is liquidated in period 1 , this incurs a liquidation cost so that the return becomes $\theta \gamma$, with $0<\theta \gamma<1<\theta R .{ }^{17}$ In this event, the proceeds of liquidation are given to the representative consumer.

The type $\theta$ represents the efficiency of a bank in managing its investment. A key informational friction is that this efficiency parameter is private information of the bank, i.e. observed by the bank but not by the regulators. For simplicity, we assume that all banks are characterized by the same $\theta$ in the economy. ${ }^{18}$ The random variable $\theta$ can have two levels $\underline{\theta}$ and $\bar{\theta}$, with associated probabilities $\nu$ and $1-\nu$, respectively. ${ }^{19}$ The distribution of $\theta$ is common knowledge. We also define $\Delta \theta:=\bar{\theta}-\underline{\theta}>0$ as the efficiency difference between high- and low-efficiency banks.

\footnotetext{
${ }^{14}$ Allowing households to store cash would not change our main results; see footnote 30 for a detailed discussion.

${ }^{15}$ In Section 8 we relax this assumption and show that our main results are qualitatively the same when we allow banks to compete for deposits. In this case the interest rate is endogenized.

${ }^{16}$ In Section 7, we show that our results remain valid if we assume that banks are affected by idiosyncratic failure shocks.

${ }^{17}$ It is reasonable to assume that banks with different efficiency capacities also liquidate with different efficiency levels. Actually an identical liquidation capacity for all banks (formally, replacing $\gamma \theta$ by $\gamma$ in the relevant equations) would slightly simplify the resolution of the model without modifying our qualitative results.

${ }^{18}$ Relaxing this assumption makes the presentation of the model more lengthy without changing our main results; see Section 7. We also do not allow the regulator to make use of the perfect correlation of types for the two banks; see the discussion in Section 6 .

${ }^{19}$ Allowing more efficiency levels does not bring interesting additional insights to our analysis. In particular our main results in Theorem 1 and Corollary 1 hold both when there is a continuum of types or when there are finitely many types.
} 
If no risky investment is undertaken, the bank's profit is normalized to zero: $\Pi(\theta)=0$, for all $\theta$. When the risky investments fails and the bank is liquidated, its profit is normalized to zero for any $\theta$ as the regulatory authority seizes all existing assets. Hence, the expected profit of a bank of type $\theta$ is given by

$$
\pi(\theta)=\rho d(\theta R-1)
$$

where $d$ denote the amount invests invested in the risky asset.

Financial integration. We define international financial integration as the free capacity to banks to choose the regulator under which they operate even though their depositors reside in a given country. This is equivalent to assuming that banks in a given country are free to set up subsidiaries in any country, taking advantage of the international mobility of financial flows.

Since a bank is not constrained on its location decision, this choice depends on the comparison of the expected profits under the offered regulatory contracts: a bank locates in the country where the most profitable regulatory contract is offered, i.e. the contract that leads to the highest expected profit given its efficiency level. Consequently the number of banks located in Country $j$, which we denote by $n_{j}$, is not fixed a priori but results from this comparison: $n_{j} \in\{0,1,2\}, \forall j$.

A bank has two decisions to make: (i) the choice of location, or equivalently of its regulator, and (ii) the choice of its portfolio allocation of $D$ between liquid and illiquid assets. Both choices follow from the profit maximization of the bank. In particular, absent regulation, it follows from the assumption $\theta R>1$ that the bank profit maximization leads to investing all deposits into the risky asset, i.e. $d=D$.

\subsection{Regulation}

In each country a regulator or (local) public authority, denoted by $P_{j}$, is in charge of the design of banking regulation. Each regulator is a mechanism designer (principal) that faces two sets of constraints. First, it must take into account its information disadvantage with respect to banks about their efficiency levels (information constraints). Second, it need to ensure banks are willing to operate in its jurisdiction (participation constraints).

These constraints in each country describe the set of allocations that a principal can achieve despite its lack of information. On a general level, an allocation is an output that is reached and a distribution of the gains from trade. In our environment, an output is a chosen risk-related asset portfolio and the distribution of the gains from trade that corresponds to the distribution of profits generated by portfolio decisions. 
We now introduce the regulatory instruments that will prove to be necessary and sufficient for implementing optimal regulatory contracts. First, banks' portfolios are regulated by means of liquidity requirements, $F_{j} \geq 0$, such that the assets put at risk are $d_{j}=D-F_{j}$. Second, taxes are levied on profit so as to control the rent of banks, $T_{j} \geq 0 .^{20}$ These instruments are more general that their labels may suggest. What is important is that there are instruments that affect the degree of the riskiness of banks' portfolio and regulate the overall profit of banks.

In the case of incomplete information and $D>F_{j}$, we study direct revelation mechanisms in which a regulatory contract designed by the regulator in country $j$ is a couple $\left\{F_{j}(\widetilde{\theta}), T_{j}(\widetilde{\theta})\right\}$, where $F_{j}($.$) and T_{j}($.$) denote respectively the share of liquid asset (port-$ folio) and the taxes on profits as functions of the report of the bank about its efficiency, $\widetilde{\theta}$, in Country $j .{ }^{21}$

We denote by $\underline{F}_{j}$ and $\bar{F}_{j}$ the shares of liquid asset imposed in Country $j$ on a bank of efficiency $\underline{\theta}$ and $\bar{\theta}$ respectively, and by $\underline{T}_{j}$ and $\bar{T}_{j}$ the respective taxes levied on the bank with efficiency $\underline{\theta}$ and $\bar{\theta}$.

Admissible regulatory contracts. Our approach provides a rigorous foundation to the constraints that a regulator faces: privately held information gives rise to incentive compatibility constraints; the requirement of voluntary participation leads to the imposition of participation constraints.

The participation constraints ensure the break-even condition of the bank under the different regulatory schemes. Formally, for all $j$, the profit of a bank $\theta \in\{\underline{\theta}, \bar{\theta}\}$ subject to the regulation in Country $j$ is:

$$
\begin{aligned}
& \Pi_{j}(\bar{\theta})=\rho\left[\left(D-\bar{F}_{j}\right)(R \bar{\theta}-1)-\bar{T}_{j}\right] \geq 0, \\
& \Pi_{j}(\underline{\theta})=\rho\left[\left(D-\underline{F}_{j}\right)(R \underline{\theta}-1)-\underline{T}_{j}\right] \geq 0 .
\end{aligned}
$$

Second, as the efficiency of the bank is the bank's private information, the public authority is not able to assign the bank to a particular regulatory scheme. When designing banking regulation, it has to ensure that the bank chooses the regulatory scheme that is socially optimal for the bank's level of efficiency. This introduces some self-selection or incentive compatibility constraints to the problem of the regulator for all $j$ :

$$
\Pi_{j}(\bar{\theta}, \bar{\theta})=\rho\left[\left(D-\bar{F}_{j}\right)(R \bar{\theta}-1)-\bar{T}_{j}\right] \geq \Pi_{j}(\bar{\theta}, \underline{\theta})=\rho\left[\left(D-\underline{F}_{j}\right)(R \bar{\theta}-1)-\underline{T}_{j}\right]
$$

\footnotetext{
${ }^{20}$ Ruling out the possibility of subsidies, i.e. $T_{j}$ cannot be negative, is without loss of generality; see our discussion in the Proof of Theorem 1.

${ }^{21} \mathrm{By}$ the Revelation Principle, it is without loss of generality to restrict attention to direct revelation mechanisms in which banks tell the truth about their type, see Laffont and Martimort (2002).
} 


$$
\Pi_{j}(\underline{\theta}, \underline{\theta})=\rho\left[\left(D-\underline{F}_{j}\right)(R \underline{\theta}-1)-\underline{T}_{j}\right] \geq \Pi_{j}(\underline{\theta}, \bar{\theta})=\rho\left[\left(D-\bar{F}_{j}\right)(R \underline{\theta}-1)-\bar{T}_{j}\right] .
$$

These constraints ensure that any bank prefers to truthfully report its efficiency rather than a different level of efficiency and accepts the regulations associated with that efficiency level.

Regulatory arbitrage: location decision of banks. Given the mobility of banks, each regulator competes with its counterpart. As said above, the location decision of banks depends on the comparison of profits under the different regulatory contracts offered by the regulators: a bank locates in the country in which it maximizes its expected profit. Formally, the number of banks choosing the contract offered in Country $j$, denoted by $n_{j}$, is given by the following rule: for a given $\theta$,

$$
n_{j}=\left\{\begin{array}{l}
2, \text { if } \Pi_{j}(\theta)>\Pi_{-j}(\theta), \\
1, \text { if } \Pi_{j}(\theta)=\Pi_{-j}(\theta), \\
0, \text { if } \Pi_{j}(\theta)<\Pi_{-j}(\theta) .
\end{array}\right.
$$

As follows from equation (6), one bank is located in each country when profits are equal across jurisdictions. In this case we assume without loss of generality that a bank operates in the country where it collects deposits. Our assumption of perfect mobility shows in the most transparent way how regulatory contracts are affected by competing regulators. We show the conditions under which our results carry through under imperfect mobility in Section 7.

Welfare. The regulator in Country $j$ cares about the welfare of the representative household living in Country $j .^{22}$

The proceeds of taxation $\mathfrak{T}_{\mathfrak{j}}$ raised in country $j$ are transferred to the representative household residing in this country. The amount of taxes collected depends both on the taxation scheme applied to banks by $P_{j}$ and the number of banks contracting with it. Formally, $\mathfrak{T}_{\mathfrak{j}}$ is equal to $n_{j} T_{j}$, where $n_{j}$ is determined by (6). This creates an incentive for $P_{j}$ to attract banks.

If all regulators forbid investments in the risky asset, i.e. $F_{j}(\theta)=D$ for all $j$ and all $\theta$, given the availability of the liquid asset at all period, and the desire of consumers to

\footnotetext{
${ }^{22}$ We extend our model in Section 7 to include banks' profit that are located in a jurisdiction in the welfare objective of regulator. The qualitative properties of our main results would not be affected when the regulator puts more weights on consumer's surplus than on banks' profit. This is a standard assumption in the regulatory literature, see Laffont and Tirole (1993).
} 
smooth consumption, the initial endowment is divided in two and consumed equally in every period. ${ }^{23}$ Thus the welfare is given by

$$
2 \cdot U\left(\frac{D}{2}\right) .
$$

If some risky investment is allowed under the contract of regulator $P_{j}$, i.e. $D>F_{j}$ for all $\theta$, its welfare depends on the location choice of banks and thus both on the contract terms they choose to apply to their customers and the number of banks located in $j$.

In the case of liquidation of a bank of type $\theta$, the regulator has access to the safe asset technology so as to make transfers from period 1 to period 2. The utility of the representative household, given the desire of consumers to smooth consumption, is then given by

$$
2 \cdot U\left(\frac{F_{j}(\theta)+\left(D-F_{j}(\theta)\right) \gamma \theta}{2}\right) .
$$

When no liquidation occurs, if the bank with a customer based in Country $j$ chooses the regulatory contract in Country $-j$, the contractual terms benefit to the household in Country $j$. Formally, the representative household in Country $j$ receives $F_{-j}$ in the first period and $D-F_{-j}$ in the second period.

We now detail the expressions of the welfare function of the regulator in Country $j$ depending on the number of banks located in its jurisdiction.

If the comparison of profits is such that no bank locates in Country $j$, there will be no tax receipts in $j$ and the consumption level of households in $j$ is determined by the contract offered in Country $-j$. Thus the expected welfare of $P_{j}$ contracting with no bank in its jurisdiction is given by

$$
\begin{aligned}
& \mathcal{W}_{j}^{0}=\nu\left\{\rho\left[U\left(\underline{F}_{-j}\right)+U\left(D-\underline{F}_{-j}\right)\right]+(1-\rho) \cdot 2 \cdot U\left(\frac{\underline{F}_{-j}+\left(D-\underline{F}_{-j}\right) \gamma \underline{\theta}}{2}\right)\right\} \\
& +(1-\nu)\left\{\rho\left[U\left(\bar{F}_{-j}\right)+U\left(D-\bar{F}_{-j}\right)\right]+(1-\rho) \cdot 2 \cdot U\left(\frac{\bar{F}_{-j}+\left(D-\bar{F}_{-j}\right) \gamma \bar{\theta}}{2}\right)\right\} .
\end{aligned}
$$

If banks' profits are equal, then banks locate in their initial jurisdiction and there is one bank in Country $j$, applying the contract offered by $P_{j}$. Thus the expected welfare of $P_{j}$ is given by

$$
\begin{aligned}
& \mathcal{W}_{j}^{1}=\nu\left\{\rho\left[U\left(\underline{F}_{j}\right)+U\left(D-\underline{F}_{j}+\underline{T}_{j}\right)\right]+(1-\rho) \cdot 2 \cdot U\left(\frac{\underline{F}_{j}+\left(D-\underline{F}_{j}\right) \gamma \underline{\theta}}{2}\right)\right\} \\
& +(1-\nu)\left\{\rho\left[U\left(\bar{F}_{j}\right)+U\left(D-\bar{F}_{j}+\bar{T}_{j}\right)\right]+(1-\rho) \cdot 2 \cdot U\left(\frac{\bar{F}_{j}+\left(D-\bar{F}_{j}\right) \gamma \bar{\theta}}{2}\right)\right\} .
\end{aligned}
$$

\footnotetext{
${ }^{23}$ In our environment the regulator will always allow some investment to be undertaken as soon as the risky assets are sufficiently profitable, i.e. the net present value (NPV) is sufficiently high.
} 
Finally, if the comparison of profits is such that all banks locate in $j$ and thus apply the contract offered by $P_{j}$, the expected welfare of $P_{j}$ is given by:

$$
\begin{aligned}
& \mathcal{W}_{j}^{2}=\nu\left\{\rho\left[U\left(\underline{F}_{j}\right)+U\left(D-\underline{F}_{j}+2 \underline{T}_{j}\right)\right]+(1-\rho) \cdot 2 \cdot U\left(\frac{\underline{F}_{j}+\left(D-\underline{F}_{j}\right) \gamma \underline{\theta}}{2}\right)\right\} \\
& +(1-\nu)\left\{\rho\left[U\left(\bar{F}_{j}\right)+U\left(D-\bar{F}_{j}+2 \bar{T}_{j}\right)\right]+(1-\rho) \cdot 2 \cdot U\left(\frac{\bar{F}_{j}+\left(D-\bar{F}_{j}\right) \gamma \bar{\theta}}{2}\right)\right\} .
\end{aligned}
$$

These expressions make clear that the sole cross-border spillover in the economy is due to the regulatory arbitrage by banks, linked to the competition between regulators and their non-cooperative behavior.

Why do we need to regulate banks' activities? In our environment, banks do not internalize the consequences of their risk-taking activities on consumer's welfare. Because it is liquidated in case of failure at no cost for the banker, a profit-maximizing bank always decides on a riskier portfolio than what would be socially optimal from consumers' perspective. Therefore the consumption-smoothing motive embodied in the welfare function of a regulator requires that a share of deposits is kept in the liquid asset, whereas banks invest all deposits in the risky asset if they are no forced by regulators to hold some liquid asset. In other words, in the absence of regulation, the output reached would not be efficient from a welfare perspective.

The regulatory game. All decisions by the regulators and the banks are made in period 0 . The timing of these decisions is as follows:

(i) Households are allocated to their country's representative bank. Each bank learns its own type $\theta$. The distribution of types is common knowledge across agents.

(ii) The local regulators offer non-cooperatively and simultaneously their regulatory contracts, i.e. a set of regulations to banks which may be contingent on its efficiency. Banks decide whether or not to agree to participate. If both banks reject the type-dependent contracts, the contract $D=F_{j}$, for all $j$, is implemented.

(iii) Banks report about their efficiency level to the public authority they chose. The regulatory contracts are implemented accordingly.

A strategy of $P_{j}$, with $j=1,2$, is a vector $\left(\bar{F}_{j}, \bar{T}_{j}, \underline{F}_{j}, \underline{T}_{j}\right)$ belonging to the set of admissible contracts. A Nash equilibrium of the regulatory game is a vector

$$
\left(\bar{F}_{1}, \bar{T}_{1}, \underline{F}_{1}, \underline{T}_{1}, \bar{F}_{2}, \bar{T}_{2}, \underline{F}_{2}, \underline{T}_{2}, n_{1}, n_{2}\right)
$$


such that for all $j=1,2,\left(\bar{F}_{j}, \bar{T}_{j}, \underline{F}_{j}, \underline{T}_{j}\right)$ in the set of admissible contracts are mutually optimal replies.

\section{Optimal regulation without competing regulators}

As a benchmark we first detail the optimal regulatory contract designed by a national public authority regulating the national bank in the absence of regulatory arbitrage. ${ }^{24}$ More simply, we assume a closed economy in which the regulator faces a (representative) bank.

The problem of the regulator $j$ in this case is to maximize $\mathcal{W}_{j}^{1}$ given by $(8)$, with respect to $\left(\underline{F}_{j}, \bar{F}_{j}, \underline{T}_{j}, \bar{T}_{j}\right)$ subject to $(2),(3),(4),(5)$.

We denote with a superscript $S$ the optimal regulatory contract in this configuration and we drop the subscript $j$ since we consider a single country.

Proposition 1 The regulatory contract offered when a regulator does not compete for attracting banks to its jurisdiction is such that

(i) the less efficient bank is subject to more stringent liquidity requirement than the efficient one: $\underline{F}^{S}>\bar{F}^{S}$ where

$$
\begin{gathered}
\rho U^{\prime}\left(\underline{F}^{S}\right)+(1-\rho)(1-\gamma \underline{\theta}) U^{\prime}\left(\frac{\underline{F}^{S}+\left(D-\underline{F}^{S}\right) \gamma \underline{\theta}}{2}\right) \\
=\rho R \underline{\theta} U^{\prime}\left(D-\underline{F}^{S}+\underline{T}^{S}\right)-\frac{1-\nu}{\nu} \rho R(\bar{\theta}-\underline{\theta}) U^{\prime}\left(D-\bar{F}^{S}+\bar{T}^{S}\right),
\end{gathered}
$$

and

$$
\rho U^{\prime}\left(\bar{F}^{S}\right)+(1-\rho)(1-\gamma \bar{\theta}) U^{\prime}\left(\frac{\bar{F}^{S}+\left(D-\bar{F}^{S}\right) \gamma \bar{\theta}}{2}\right)=\rho R \bar{\theta} U^{\prime}\left(D-\bar{F}^{S}+\bar{T}^{S}\right)
$$

(ii) the less efficient bank is subject to a lower but positive tax level than the efficient one: $0<\underline{T}^{S}<\bar{T}^{S}$ where

$$
\underline{T}^{S}=\left(D-\underline{F}^{S}\right)(R \underline{\theta}-1),
$$

and

$$
\bar{T}^{S}=\left(D-\bar{F}^{S}\right)(R \bar{\theta}-1)-R(\bar{\theta}-\underline{\theta})\left(D-\underline{F}^{S}\right) ;
$$

(iii) the efficient bank expects positive profit, i.e. $\bar{\Pi}^{S}>0$, whereas the less efficient one expects no profit: $\underline{\Pi}^{S}=0$.

\footnotetext{
${ }^{24}$ In Appendix $\mathrm{C}$ we also provide the complete information optimal regulatory contract in the absence of arbitrage.
} 
The optimal banking regulation described in Proposition 1 exhibits the control of both the riskiness of the bank's portfolio and the profit generated from its investment decision. More specifically, an efficient bank is allowed to take more risk than an inefficient one, and is more taxed. The levels of liquidity for each type of banks are implicitly pinned down by equations (10) and (11). The left-hand side of these equations gives the expected marginal benefit of increasing the liquidity for first-period consumption and for second-period consumption in case of failure of the risky investment. The right-hand side describes the expected marginal cost associated to the liquidity requirement when the state of nature is favorable. Notice that the last term on the right-hand side of equation (10) represents a decrease in the expected marginal cost associated to the liquidity requirement when the bank is inefficient. This term comes from the informational friction between the bank and the regulator: by increasing the liquidity requirement of the most inefficient bank the regulator decreases the informational rent left to the efficient bank to encourage selfselection into the regulatory scheme designed for its risk-taking behavior. Yet an efficient bank's profit is strictly positive.

The optimal regulatory contract is an efficiency-contingent contract: banks of different types adopt different regulations. This separation result is consistent with the traditional regulatory literature on discriminatory regulatory schemes: the difference in efficiency levels is reflected in the regulatory contract by allowing a more efficient bank to choose a riskier portfolio.

It is important to notice that the liquidity requirement and the tax level that the bank faces are interdependent: the two regulatory instruments are calibrated to allow discrimination based on the efficiency of the bank and together form a contract included in the set of admissible regulatory contracts. In particular, taxation is used both to give to the consumer a share of the profits generated by the investments and adjust banks' profits consistently with a separating contract. We show in the following that the possibility of such a fine-tuned regulation is drastically affected when regulators are put in competition.

\section{Banking regulation in a financially integrated economy}

We now return to the two-country economy where banks are free to choose their regulatory contracts according to which they operate. The integration of financial markets compels regulators to consider the location decisions of banks.

The following theorem states our main result. We provide a complete equilibrium characterization in Corollary 1 below. Its existence is shown in Appendix B. 
Theorem 1 Under financial integration the unique Nash Equilibrium of the regulatory game is a simple pooling contract where all banks are subject to the same liquidity regulation independently of their efficiency levels and pay no taxes on profits.

Theorem 1 shows that opening the possibility for banks to choose their regulators leads to a simple regulatory contract identical in both countries. This contract has two important features. First, it treats all banks alike independently of their efficiency levels. Hence our model predicts that banking regulation does not imply sophisticated discrimination between banks since they are subject to the same rule. Second, within the set of allocations that are incentive-compatible and satisfy participation constraints, the regulatory equilibrium pins down an allocation that is inefficient in term of risk-taking investment and where no redistribution of gains from investment occurs. Such equilibrium is obtained because one of the instruments in the set of regulatory tools cannot be activated and used by the regulators in a Nash equilibrium when there is regulatory arbitrage: no taxes are levied on banks' profits. That is, the mobility of banks leads to the loss of one regulatory instrument (taxes) in both countries. A regulator with only one instrument left (liquidity requirement) cannot calibrate it so as to allow discrimination of banks based on their efficiency levels. In an incomplete information environment where banks choose to locate their activities under the most favorable regulation, Theorem 1 states that the regulatory equilibrium generates a unique liquidity requirement, defining the extent of risk being taken by banks, valid for all banks independently of their efficiency levels. Thus banking regulation is inefficient under financial integration insofar as it is unable to discriminate among diversely efficient banks.

The complete characterization of the Nash Equilibrium contract is gathered in the following corollary and denoted with a superscript $N$.

Corollary 1 The unique Nash Equilibrium of the regulatory game

$$
\left(\bar{F}_{1}^{N}, \bar{T}_{1}^{N}, \underline{F}_{1}^{N}, \underline{T}_{1}^{N}, \bar{F}_{2}^{N}, \bar{T}_{2}^{N}, \underline{F}_{2}^{N}, \underline{T}_{2}^{N}, n_{1}^{N}, n_{2}^{N}\right)
$$

when regulators compete for attracting banks to their jurisdiction is such that

(i) the taxes are null for all types of banks in the two countries: $T^{N}:=\underline{T}_{j}^{N}=\bar{T}_{j}^{N}=0$, for all $j$;

(ii) both the inefficient and the efficient bank faces the same liquidity regulation $F^{N}:=$ $\bar{F}_{j}^{N}=\underline{F}_{j}^{N}$, for all $j$, defined by

$$
\rho U^{\prime}\left(F^{N}\right)+(1-\rho)\left\{\nu(1-\gamma \underline{\theta}) U^{\prime}\left(\frac{F^{N}+\left(D-F^{N}\right) \gamma \underline{\theta}}{2}\right)\right.
$$




$$
\left.+(1-\nu)(1-\gamma \bar{\theta}) U^{\prime}\left(\frac{F^{N}+\left(D-F^{N}\right) \gamma \bar{\theta}}{2}\right)\right\}=\rho U^{\prime}\left(D-F^{N}\right)
$$

(iii) each country has one bank: $n^{N}:=n_{1}^{N}=n_{2}^{N}=1$;

(iv) all types of banks expect positive profits: $\bar{\Pi}_{j}^{N}>\underline{\Pi}_{j}^{N}>0$, for all $j$.

The intuition for the proof is the following: banks are sensitive to after-tax profits and profits depend both on the tax level and the amount of risky investment allowed by the regulators. The possibility for banks to choose their location generates a conflict between non-cooperating national regulators. In each country, the regulator wants to restrain the impulse of banks to make too risky investments as it would negatively affect the welfare of its residents. Yet it views the coming of a bank in its jurisdiction as an enlargement of its taxation base leading to an increase in the residents' welfare. By slightly diminishing the level of taxes, the regulator expects to compensate the loss of revenues per bank by attracting more banks so as to obtain an increase in the total amount of taxes received and transferred to its residents. However the logic of undercutting taxes leads to an aggressive underbidding à la Bertrand which forces both regulators to drive down all taxes to zero.

As far as the liquidity regulation in the equilibrium is concerned, there is a unique level of liquidity for banks irrespective of their type. This unique and inefficient liquidity requirement for both types of banks results from the loss of the tax instrument. When taxes are null both incentive compatibility constraints (4) and (5) are binding, and the only liquidity regulation satisfying both of them is the pooling one defined in equation (14). In other words, the Nash equilibrium of this game is a simple pooling equilibrium. Regulators are unable to overcome (at least partially) their information disadvantage and differentiate the banks in presence of regulatory arbitrage.

Finally, the most efficient bank is more profitable than the less efficient one, and for both types of banks profits obtained under the pooling equilibrium are strictly positive. As we discuss below, this last result has important implications for the possible resistance of the banking industry to regulatory changes.

\section{The benefits of integrating regulation}

Given the failure of regulation in a financially open economy when regulation is left to separated national regulators, we turn to the issue of affecting the regulation task to a single authority in charge of regulating all banks. We label this authority the "integrated 
regulator". In practice it can be thought either as a supra-national regulator or cooperative regulation between several agencies. We first show what are the regulatory contracts in our economy if banks are subject to an integrated regulator. We then compare the regulatory contracts obtained under either competing or integrated regulators.

Integrated regulator. An integrated regulator cares about all residents in the two countries and weighs welfare equally. We characterize the optimal regulatory contracts offered by the integrated regulator. The symmetry of the economy implies that there is no reason to offer different contracts in the two countries. Hence the location rule implies that there is one bank in each country. Thus the welfare is the same in both countries and the problem of the integrated authority under incomplete information is to maximize $\mathcal{W}_{1}^{1}+\mathcal{W}_{2}^{1}$, with $\mathcal{W}_{j}^{1}$ given by (8), with respect to $\left(\underline{F}_{j}, \bar{F}_{j}, \underline{T}_{j}, \bar{T}_{j}\right)$ subject to (2), (3), (4), (5).

We do not allow the regulator to make use of the perfect correlation of types for the two banks, i.e. "yardstick competition" is not possible. ${ }^{25}$ Allowing regulator to use this correlation would give to the integrated regulator an informational advantage with respect to the competing ones which would bias our comparison in Proposition 3. In the proposition below we drop the subscript $j$ since the two countries are symmetric.

Proposition 2 Under integrated regulation, the regulatory contract offered is such that

(i) the less efficient bank faces a lower but positive tax level than the efficient one: $0<$ $\underline{T}^{S}<\bar{T}^{S}$ where $\underline{T}^{S}$ and $\bar{T}^{S}$ are defined by (12) and (13) respectively;

(ii) the less efficient bank faces more stringent liquidity requirement than the efficient one: $\underline{F}^{S}>\bar{F}^{S}$, where $\underline{F}^{S}$ and $\bar{F}^{S}$ are defined by (10) and (11) respectively;

(iii) each country has one bank: $n^{S}:=n_{1}^{S}=n_{2}^{S}=1$;

(iv) the efficient bank expects positive profit, i.e. $\bar{\Pi}^{S}>0$, whereas the less efficient one expects no profit: $\underline{\Pi}^{S}=0$.

Proposition 2 shows that an integrated regulator would offer the discriminatory regulatory contract equal to the one obtained in a closed economy with a single regulator

\footnotetext{
${ }^{25}$ Since types are correlated, an integrated regulator would like to use the report of one bank to incentivize the other bank. Under correlation of types, the optimal regulation of one bank may depend not only on its reported type but also on the report by the other bank. This introduces yardstick competition between banks. It is well-known in the industrial organization literature that this kind of competition helps the regulator to reduce the social cost of providing incentives (see, for instance, Shleifer, 1985).
} 
which was the subject of Section 4. In particular integrated regulation reintroduces the tax instruments which allow discrimination of risk levels according to types of banks. Notice that this result hinges on the fact that the sole cross-border spillover present in our economy is through the mobility of banks, linked to the competition between regulators and their non-cooperative behaviors. Once we remove this competition by allowing regulators to cooperate the optimal separating contract is recovered. The banks are allocated equally to the two jurisdictions and no redistribution between jurisdictions is necessary to obtain the optimal allocation.

Comparison. We now compare the two regulatory contracts with and without regulatory integration, and their impacts on the banking system. In order to make this comparison we introduce the following assumption.

Assumption 1 For all $R>0$ and $x \in(0, D), R U^{\prime}(R x)$ is increasing in $R$.

Assumption 1 corresponds to a restriction on the curvature of $U(\cdot)$. It implies that an increase in the return of the risky asset augments the investment in this asset. It is similar to assuming that substitution effects dominate income effects in a static labor supply problem. It will play a role only when we compare the levels of risks taken by banks under competing and integrated regulators (see Part (iii) in the following proposition).

Proposition 3 The optimal contracts under integrated regulation and competing regulators are such that

(i) both the efficient and the inefficient banks face less taxes in the regulatory equilibrium with competing regulators than under integrated regulation: $\bar{T}^{S}>\underline{T}^{S}>T^{N}=0$;

(ii) if $\Delta \theta$ is sufficiently small, the expected profits of both the efficient and inefficient banks in the regulatory equilibrium with competing regulators are strictly higher than under integrated regulation: $\underline{\Pi}^{N}>\underline{\Pi}^{S}=0$ and $\bar{\Pi}^{N}>\bar{\Pi}^{S}>0$;

(iii) if $\Delta \theta$ is sufficiently small and if Assumption 1 holds, all banks face less stringent liquidity regulations when regulation is integrated than in the presence of competing regulators: $F^{N}>\underline{F}^{S}>\bar{F}^{S}$.

Proposition 3 shows that taxes are unambiguously lower in the regulatory equilibrium with competing regulators than under integrated regulation. However, a main insight is that the amount invested in the risky asset may be higher for any type of banks under regulatory integration than in the case of competing regulators (Part (iii) of Proposition 
3). Notice that this statement holds when the informational gap between the regulators and the banks is small which is the interesting case to consider. Intuitively, banks derive some informational rents that are functions of the difference between high- and lowefficiency banks. An integrated regulator is adjusting its two instruments to minimize the rents whereas competing regulators have only one instrument left. The smaller the difference $\Delta \theta$ the lower the informational advantage for the efficient banks. Thus our result highlights the effect of competition (i.e. losing an instrument) on liquidity regulations instead of reflecting the level of informational asymmetry between the banks and the regulators. Proposition 3 (iii) shows that once the possibility to regulate banks with several instruments is restored through the integration of regulators, banks are allowed to take more risks. An interesting implication of our model is that the traditional race-to-the-bottom result in regulatory standards does not hold in this case: the aggregate level of risks taken by banks can be higher under the optimal efficiency-specific regulatory contracts than under the pooling contract resulting from competing regulators.

A second important implication of Proposition 3 is that profits of both efficient and inefficient banks are larger under regulatory competition than under integrated regulation. Again this result is not driven by the different informational gap between the regulators and the banks since we consider a small difference between high- and lowefficiency banks (i.e. $\Delta \theta$ small). Hence, our model shows that it is possible that both types of banks strictly benefit from the regulatory competition. If its profit is a measure of the lobbying capacity of a bank, we should expect more "too-powerful-to-fail" banking institutions under competing regulators (see the propositions of Rochet (2010) and Freixas and Rochet (2013) to tackle this issue).

\section{Alternative modeling choices}

In this section, we provide a discussion of how alternative modeling choices would affect our main result. We argue that our result in Theorem 1 extends to a model with different efficiency levels in the two countries, a model with more than two countries, or an analysis in which the liquidation of assets can affect individual banks on top of the whole banking system (i.e. micro and macro failures). We also discuss how imperfect mobility of banks and introducing many dimensions of heterogeneity between banks would affect our results. Finally, we show that our results are robust to an extension of our model where both the profits of banks located in a country and the consumer welfare are in the objective function of national regulators. 
Differences in bank efficiency. In the previous sections, we assumed that all banks in the economy are characterized by the same level of efficiency, either $\bar{\theta}$ or $\underline{\theta}$. Let us now suppose that the efficiency realizations may differ for the two representative banks. Then four cases can arise, including the two cases where both banks are highly efficient or both lowly efficient we have just studied. The two other cases are when the bank servicing residents in Country $j$ has high (resp. low) efficiency whereas the bank servicing residents in Country $-j$ has low (resp. high) efficient.

Under an integrated regulator, the possibility of different efficiency levels across banks does not change our result. As we discuss in Section 6, the correlation was not used by the regulator. The regulatory contract which it sets is thus given in Proposition 2.

When regulators set their contracts non-cooperatively and banks can be of different types in the two jurisdictions, the expressions of welfare for principals are modified.

In the case where no bank settles in Country $j$, the expression of welfare in equation (7) remains unchanged. With probability $\nu$ (resp. $1-\nu$ ), the representative household $j$ will be serviced by a low (resp. high) efficient bank and there will be no tax receipt in Country $j$.

In the case where one bank settles in Country $j$, equation (8) remains unchanged too. Indeed when each country hosts a bank, the profits are equalized in both countries for a bank of a given type. As in the core of the analysis we consider that the bank servicing the representative household $j$ chooses the contract of $P_{j}$ when profits in the two jurisdictions are equal. Hence equation (8) represents the welfare in this case.

The expression of welfare in the case where all banks settle in Country $j$ in equation (9) is slightly modified. If the attracted bank is of a different type, it generates a different amount of tax. Thus expected taxes are modified. If household in Country $j$ is serviced by a low (resp. high) efficient bank, it does not imply that all banks are low (resp. high) efficient and generate $2 \underline{T}_{j}$ (resp. $2 \bar{T}_{j}$ ). The other bank may be efficient (resp. inefficient) with a probability $1-\nu$ (resp. $\nu$ ). Thus $2 \underline{T}_{j}$ and $2 \bar{T}_{j}$ must be replaced by $\nu \underline{T}_{j}+(1-\nu) \bar{T}_{j}$.

This modification does not affect our results in Section 5. The reason is that the unique Nash equilibrium is still characterized by the property that all taxes are equal to zero independently of the assumptions made on information. Thus, as the levels of liquidity regulations and profits remain the same, Theorem 1 and Corollary 1 hold.

More than two countries. Suppose that the economy is composed by an arbitrary finite number of countries, instead of two, and that countries are symmetric. Assume that each country has a regulator, and that there are as many banks as there are countries.

Allowing the economy to have many countries does not change our results. The 
intuition for this result is the following: the location decisions of banks still follow the rule defined in equation (6) which now includes the comparison of potential profits in all countries. In particular the most profitable contract offered by $P_{j}$ attracts all banks in Country $j$. If profits are equalized, there is one bank in each country. So either there are no bank, one bank, or all the banks located in Country $j$. The sole difference in the welfare of principal of Country $j$ is that the " 2 " multiplying the total taxes is replaced by the total number of banks in equation (9). But again, since all taxes are null in equilibrium in the case of financial integration, our results of Section 5 still hold when there are many countries.

We do not tackle the issue of multinational banks investing simultaneously in several countries. In our model, there is no scale effect. In particular, the return of the risky investment is constant and not depending on the size of the investment made by a bank. Thus there is no benefit for a bank to diversify its portfolio of risky assets across many countries. The introduction of size effects, either through the assumption of the rate of return of a risky investment in one country varying with the amount invested, according to a standard assumption of concavity, or through a different taxation scheme, would lead to a more complex analysis of portfolio choice in different countries by banks and its impact of national bank regulation. This is beyond the scope of this paper which focuses on the sole feature of bank mobility.

Imperfect mobility of banks. Our main results have been derived under the assumption that banks locate their investments in the country in which it maximizes its expected profit without having to suffer mobility costs associated to the location decision. Suppose now that banks have only a fraction $\alpha \in[0,1]$ of their investment that are mobile, the remaining share has to be subject to the initial country where deposits are collected. In the polar case developed in the core of our analysis, the fraction $\alpha$ would be equal to 1 . We assume that all investments are subject to the same regulation. Now for the regulator the potential gains from attracting extra investments by reducing the taxes have to be weighted against the potential loss of the tax instrument to discriminate between types of banks that have immobile investments. Indeed in the case where Country $j$ has the most attractive contract, i.e. $\Pi_{j}(\theta)>\Pi_{-j}(\theta)$, the total fraction of deposit from Bank $j$ but only a fraction $\alpha$ of deposits from Bank $-j$ would be attracted. In this extension of our model, we can show that our main results remain valid as soon as $\alpha$ is strictly positive. Intuitively, the key difference in the welfare of principal of Country $j$ is that the " 2 " multiplying the total taxes in equation (9) is replaced by $1+\alpha$. Equation (9) determines how profitable it is for a regulator to attract all mobile 
investments. When comparing the profitable deviation from an equilibrium with positive taxes, it is still the case that the deviation toward zero taxes on profit remains profitable as soon as $\alpha$ is strictly positive. ${ }^{26}$ However, our results would be affected if the imperfect mobility opens a second dimension of heterogeneity between banks (see our discussion of multidimensional heterogeneity below).

Liquidation of assets: macro and micro failures. Up to now we have supposed that (i) the rate of liquidation $\rho$ is independent of the efficiency of the bank, and (ii) liquidation is the realization of a macro shock that leads to the failure of all banks in the economy and not solely affecting a single bank (or a subset of banks).

Assumption (ii) is done for simplicity. If we assume that each bank is affected by an idiosyncratic (micro) failure shock drawn from the same distribution, Proposition 2 still holds. In the case of competing regulators, remember that regulators propose their contracts prior to the realization of the failure shock and base them of its probability $\rho$. Thus the expressions of welfare in the case of no bank, i.e. (7), and one bank, i.e. (8), in Country $j$ are not modified. The case where all banks settle in Country $j$ is more complex since the expected amount of taxes must take into account the case where one bank fails but not the other one. Retaining the assumption that both banks are of the same type, if household in Country $j$ is serviced by a not failing low (resp. high) efficient bank, it does not imply that the other bank is not failing and thus generates $\underline{T}_{j}$ (resp. $\bar{T}_{j}$ ). More precisely, with probability $\rho^{2}$, both banks are successful and generate $2 \underline{T}_{j}$ (resp. $2 \bar{T}_{j}$ ). With probability $\rho(1-\rho)$, solely the bank in $j$ is successful and the tax receipt is $\underline{T}_{j}$ (resp. $\bar{T}_{j}$ ). To sum up, the welfare of $P_{j}$ in this case writes:

$$
\begin{aligned}
& \mathcal{W}_{j}^{2}=\nu\left\{\rho^{2}\left[U\left(\underline{F}_{j}\right)+U\left(D-\underline{F}_{j}+2 \underline{T}_{j}\right)\right]+\rho(1-\rho)\left[U\left(\underline{F}_{j}\right)+U\left(D-\underline{F}_{j}+\underline{T}_{j}\right)\right]\right. \\
& \left.+(1-\rho)^{2} \cdot 2 \cdot U\left(\frac{\underline{F}_{j}+\left(D-\underline{F}_{j}\right) \gamma \underline{\theta}}{2}\right)+\rho(1-\rho) \cdot 2 \cdot U\left(\frac{\underline{F}_{j}+\left(D-\underline{F}_{j}\right) \gamma \underline{\theta}+\underline{T}_{j}}{2}\right)\right\} \\
& +(1-\nu)\left\{\rho^{2}\left[U\left(\bar{F}_{j}\right)+U\left(D-\bar{F}_{j}+2 \bar{T}_{j}\right)\right]+\rho(1-\rho)\left[U\left(\bar{F}_{j}\right)+U\left(D-\bar{F}_{j}+\bar{T}_{j}\right)\right]\right.
\end{aligned}
$$

\footnotetext{
${ }^{26}$ In the proof of Theorem 1 for the case of low-type banks, the difference in expected welfare with imperfect mobility from the deviation for $P_{j}$ toward lower taxes is then

$$
\nu \rho[U(D-\underline{\hat{F}}+(1+\alpha) \underline{\hat{T}}-(1+\alpha) \varepsilon)-U(D-\underline{\hat{F}}+\underline{\hat{T}})],
$$

whereas it was under perfect mobility (see equation $(22)$ )

$$
\nu \rho[U(D-\underline{\hat{F}}+2 \underline{\hat{T}}-2 \varepsilon)-U(D-\underline{\hat{F}}+\underline{\hat{T}})] .
$$

Even under imperfect mobility, the deviation toward lower taxes is profitable as soon as $\alpha>0$ when $\varepsilon$ is small enough. The case of high-type banks can be shown similarly. Hence any contract with positive taxes cannot be part of a Nash equilibrium.
} 


$$
\left.+(1-\rho)^{2} \cdot 2 \cdot U\left(\frac{\bar{F}_{j}+\left(D-\bar{F}_{j}\right) \gamma \bar{\theta}}{2}\right)+\rho(1-\rho) \cdot 2 \cdot U\left(\frac{\bar{F}_{j}+\left(D-\bar{F}_{j}\right) \gamma \bar{\theta}+\bar{T}_{j}}{2}\right)\right\} .
$$

In other words, the only modification implied by different failure rates is the tax receipt in the case of all banks in the same country. But this does not modify the temptation for either regulator to reduce its required tax level by an arbitrarily small amount. Thus in equilibrium, taxes are equal to zero and all the results in Section 5 hold.

With respect to Assumption (i), we could allow for the failure rate of a bank to be a function of its type. The problem is essentially the same and results are maintained when the failure rate perfectly correlates with the type of banks. ${ }^{27}$

\section{Consumer welfare and profits of banks in the objective function of regulators.}

In the core of our analysis the regulator in Country $j$ cares only about the welfare of the representative household living in $j$. We extend our model to include the profits of banks located in a country in the welfare objective of regulator. Suppose that the regulator attaches a weight of $\lambda$ (resp. $1-\lambda$ ) to consumers' welfare (resp. banks' profit). When no bank settles in a given country a regulator, the weight on consumer's welfare is equal to 1. Thus the expected welfare of $P_{j}$ contracting with no bank in its jurisdiction remains given by equation (7).

If banks' profits are equal, then banks remain in their initial jurisdictions and there is one bank in Country $j$, applying the contract offered by $P_{j}$. Thus the expected welfare of $P_{j}$ is given by:

$$
\begin{aligned}
& \mathcal{W}_{j}^{1}=\lambda\left\{\nu\left\{\rho\left[U\left(\underline{F}_{j}\right)+U\left(D-\underline{F}_{j}+\underline{T}_{j}\right)\right]+(1-\rho) \cdot 2 \cdot U\left(\frac{\underline{F}_{j}+\left(D-\underline{F}_{j}\right) \gamma \underline{\theta}}{2}\right)\right\}\right. \\
& \left.+(1-\nu)\left\{\rho\left[U\left(\bar{F}_{j}\right)+U\left(D-\bar{F}_{j}+\bar{T}_{j}\right)\right]+(1-\rho) \cdot 2 \cdot U\left(\frac{\bar{F}_{j}+\left(D-\bar{F}_{j}\right) \gamma \bar{\theta}}{2}\right)\right\}\right\} \\
& +(1-\lambda) \rho\left\{\nu\left[\left(D-\underline{F}_{j}\right)(R \underline{\theta}-1)-\underline{T}_{j}\right]+(1-\nu)\left[\left(D-\bar{F}_{j}\right)(R \bar{\theta}-1)-\bar{T}_{j}\right]\right\} .
\end{aligned}
$$

Finally, if the comparison of profits is such that all banks locate in $j$ and thus apply the contract offered by $P_{j}$, the expected welfare of $P_{j}$ is given by:

$$
\mathcal{W}_{j}^{2}=\lambda\left\{\nu\left\{\rho\left[U\left(\underline{F}_{j}\right)+U\left(D-\underline{F}_{j}+2 \underline{T}_{j}\right)\right]+(1-\rho) \cdot 2 \cdot U\left(\frac{\underline{F}_{j}+\left(D-\underline{F}_{j}\right) \gamma \underline{\theta}}{2}\right)\right\}\right.
$$

\footnotetext{
${ }^{27}$ If the failure rate is independent of the efficiency of the bank, and both dimensions are privately known by the banks, the problem would become a multidimensional screening problem, see Armstrong and Rochet (1999) and Rochet and Stole (2003). The analysis of this case is beyond the scope of the present paper.
} 


$$
\begin{aligned}
& \left.+(1-\nu)\left\{\rho\left[U\left(\bar{F}_{j}\right)+U\left(D-\bar{F}_{j}+2 \bar{T}_{j}\right)\right]+(1-\rho) \cdot 2 \cdot U\left(\frac{\bar{F}_{j}+\left(D-\bar{F}_{j}\right) \gamma \bar{\theta}}{2}\right)\right\}\right\} \\
& +(1-\lambda) \cdot 2 \cdot \rho\left\{\nu\left[\left(D-\underline{F}_{j}\right)(R \underline{\theta}-1)-\underline{T}_{j}\right]+(1-\nu)\left[\left(D-\bar{F}_{j}\right)(R \bar{\theta}-1)-\bar{T}_{j}\right]\right\} .
\end{aligned}
$$

The inclusion of banks' profit in regulator's objective is going to affect the regulatory contracts. It is a well-known result of the regulatory literature that when regulated firms' profit are included in regulator's objective and the transfers of resources to firms are socially costly, the regulator would like to equate firms' profits to zero (see Laffont and Tirole (1993)). In our environment this implies that, when the weight associated to banks is sufficiently small (i.e. $\lambda$ is sufficiently large), the optimal regulatory contract defined in Proposition 1 still equates the profit of the inefficient bank to zero and the profit of efficient bank to their informational rents.

Redoing our analysis with the new welfare functions when $\lambda$ is sufficiently large leads to the following results, denoted with a superscript $b$.

Proposition 4 Under financial integration when regulators put sufficiently high weight on consumers' welfare ( $\lambda$ is sufficiently large), the unique Nash Equilibrium of the regulatory game

$$
\left(\bar{F}_{1}^{b}, \bar{T}_{1}^{b}, \underline{F}_{1}^{b}, \underline{T}_{1}^{b}, \bar{F}_{2}^{b}, \bar{T}_{2}^{b}, \underline{F}_{2}^{b}, \underline{T}_{2}^{b}, n_{1}^{b}, n_{2}^{b}\right)
$$

is a simple pooling contract where

(i) the taxes are null for all types of banks in the two countries: $T^{b}:=\underline{T}_{j}^{b}=\bar{T}_{j}^{b}=0$, for all $j$;

(ii) both the inefficient and the efficient bank faces the same liquidity regulation $F^{b}:=$ $\bar{F}_{j}^{b}=\underline{F}_{j}^{b}$, for all $j$, defined by

$$
\begin{gathered}
\rho U^{\prime}\left(F^{b}\right)+(1-\rho)\left\{\nu(1-\gamma \underline{\theta}) U^{\prime}\left(\frac{F^{b}+\left(D-F^{b}\right) \gamma \underline{\theta}}{2}\right)\right. \\
\left.+(1-\nu)(1-\gamma \bar{\theta}) U^{\prime}\left(\frac{F^{b}+\left(D-F^{b}\right) \gamma \bar{\theta}}{2}\right)\right\} \\
=\rho U^{\prime}\left(D-F^{b}\right)+\rho \frac{1-\lambda}{\lambda}(\nu(R \underline{\theta}-1)+(1-\nu)(R \bar{\theta}-1)) ;
\end{gathered}
$$

(iii) each country has one bank: $n^{b}:=n_{1}^{b}=n_{2}^{b}=1$;

(iv) all types of banks expect positive profits: $\bar{\Pi}_{j}^{b}>\underline{\Pi}_{j}^{b}>0$, for all $j$. 
The qualitative properties of our main results would not be affected when the regulator weighs sufficiently the consumer's surplus than the banks' profits. In particular we still obtain a unique Nash equilibrium that exhibits no taxation: the competition between regulators leads to a pooling contract for the same reason as above, which is the loss of a regulatory instrument.

Still the terms of a regulatory contract are modified since the rate of return on the risky asset and profit are modified. Since the regulator derives some welfare from banks' profit, she is interested in risk-taking activities by the bank. This affects the expected marginal cost associated to liquidity requirements, as evidenced in the right hand side of equation (17).

Multidimensional screening and banking regulation. Our analysis assumes that banks differ in one dimension of heterogeneity, namely the efficiency of investment management $\theta$. Under this assumption we have shown that two instruments are enough to implement the optimal regulatory contract, but that losing one instrument leads to our pooling result. If we introduce other dimensions of heterogeneity observable by the regulator or correlated with the type $\theta$, it is possible that losing the tax instrument would not lead to pooling. For instance, if two dimensions are introduced and the second dimension is perfectly observable, the regulators could condition their regulatory contracts on this new dimension. Thus pooling in the $\theta$ dimension would not mean pooling in all dimensions. If the second heterogeneity dimension is privately known by banks we would be in a multidimensional screening problem. For instance, suppose that the new dimension of heterogeneity is due to different mobility costs related to banks' location decision. Banks will now differ on their (additively separable) mobility cost parameter $\chi$, that could, for simplicity, take two values $\{\underline{\chi}, \bar{\chi}\}$ and that would determine how costly it is for a bank to move to Country $j .{ }^{28}$ The location decision would then be: move to Country $j$ if $\Pi_{j}(\theta)-\Pi_{-j}(\theta) \geq \chi$ instead of our location decision rule in (6). Under this specification all our results would remain valid if $\bar{\chi}$ is sufficiently small (where the sufficiently small refers to the existence condition we derive in Appendix B). At the other extreme if $\underline{\chi}$ becomes very large we would be back to our benchmark without competing regulators. For intermediate range of $\chi$ our results may be affected both in terms of existence of an equilibrium and the possibility to sustain separating equilibria. We leave for future research a complete analysis of this case.

\footnotetext{
${ }^{28}$ This formalization is in line with the random participation models adopted in the literature on competitions over nonlinear income taxes - see, e.g., Lehmann et al. (2014) - and in industrial organization - see, e.g., Rochet and Stole (2002) or Armstrong and Vickers (2001).
} 


\section{Competition between banks for deposits}

An important aspect of financial integration is the improvement of services that consumers may enjoy from the increase of competition in the banking sector. In order to take this effect into account we extend our analysis to the case where banks are now competing for deposits instead of being granted monopoly power on resident depositors. Households are now no longer assigned ex-ante to a bank, and can benefit from competition for deposits between banks. Such a competition forces banks to improve the terms of their deposit contract (above returns normalized to 1 in the core of our analysis) so as to attract or retain customers. As this would affect banks' profit this is likely to modify substantially the terms of the regulatory contracts.

As in our analysis above, the (local/incumbent) representative bank in $j$ receives deposits $D$. However we now assume that only a fraction $\alpha \in[0,1]$ of these deposits are assigned definitively to this bank. The remaining fraction $1-\alpha$ is contested by potential (entrant/foreigner) bank. Said differently, the representative bank has market power on a fraction of deposits, but the other part will go to the bank offering the best deal among those offered by banks, both incumbent or potential entrant.

We assume that there is perfect competition between the incumbent and the potential entrant for the contestable share of deposits such that any bank offers the best terms for this share. Therefore it makes zero net profit on the contestable share deposits as it abandons its rent on it to the representative household. The presence of competition among banks leads to a reduction in informational rents of banks. Our previous results correspond to an extreme case of this extension with the assumption of no bank competition, i.e. $\alpha=1$. We now study cases where $\alpha<1$.

The regulatory contract chosen by a bank applies uniformly to all deposit contracts offered to depositors. To simplify exposition we reason in the case of a bank of type $\theta$ and we denote by $\left(F_{j}, T_{j}\right)$ the contract offered to it by $P_{j}$. The total expected profit of a bank under this contract is defined as:

$$
\alpha \pi_{j, \alpha}+(1-\alpha) \pi_{j, 1-\alpha}=\alpha\left\{\left(D-F_{j}\right)(R-1) \theta-T_{j}\right\}+(1-\alpha)\left\{\left(D-F_{j}\right)\left(R-r_{j}\right) \theta-T_{j}\right\},
$$

where $\pi_{j, \alpha}$ denotes the profit made on the assigned fraction of deposit and $\pi_{j, 1-\alpha}$ the profit made on the contestable fraction under the regulatory contract of Country $j$. Finally, the rate of return set on the contestable deposit market is denoted by $r_{j} \in[1, R]$.

We keep the assumption that all banks in the economy have the same efficiency level. For the contestable fraction of deposit, the representative bank of type $\theta$ makes no profit on its illiquid investment when successful: the consumer obtains the whole net return on the risky asset through the rate that the bank serves. This defines the rate of return $r_{j}$ 
proposed in the deposit contract for contestable deposits. It is such that

$$
\pi_{j, 1-\alpha}=0 \Leftrightarrow\left(D-F_{j}\right)\left(R-r_{j}\right) \theta-T_{j}=0 .
$$

The solution of this equation, denoted by $r_{j}^{e}$, is given by

$$
r_{j}^{e}=R-\frac{T_{j}}{\left(D-F_{j}\right) \theta} .
$$

Using equation (18) we get the consumption level of household $j$ in period 2:

$$
\begin{aligned}
c_{2}= & \alpha\left(D-F_{j}\right)+(1-\alpha)\left[\left(D-F_{j}\right) \theta r_{j}^{e}\right]+T_{j} \\
& =\left(D-F_{j}\right)(\alpha+(1-\alpha) R \theta)+\alpha T_{j} .
\end{aligned}
$$

Thus the expected welfare of the public authority in Country $j$ contracting with no bank becomes (if some risky investment are made):

$$
\begin{gathered}
\nu\left\{\rho\left[U\left(\underline{F}_{-j}\right)+U\left(\left(D-\underline{F}_{-j}\right)(\alpha+R \underline{\theta}(1-\alpha))\right)\right]+(1-\rho) \cdot 2 \cdot U\left(\frac{\underline{F}_{-j}+\left(D-\underline{F}_{-j}\right) \gamma \underline{\theta}}{2}\right)\right\} \\
+(1-\nu)\left\{\rho\left[U\left(\bar{F}_{-j}\right)+U\left(\left(D-\bar{F}_{-j}\right)(\alpha+R \bar{\theta}(1-\alpha))\right)\right]+(1-\rho) \cdot 2 \cdot U\left(\frac{\bar{F}_{-j}+\left(D-\bar{F}_{-j}\right) \gamma \bar{\theta}}{2}\right)\right\} .
\end{gathered}
$$

The expected welfare of the public authority in Country $j$ contracting with one bank is given by:

$$
\begin{gathered}
\nu\left\{\rho\left[U\left(\underline{F}_{j}\right)+U\left(\left(D-\underline{F}_{j}\right)(\alpha+(1-\alpha) R \underline{\theta})+\alpha \underline{T}_{j}\right)\right]+(1-\rho) \cdot 2 \cdot U\left(\frac{\underline{F}_{j}+\left(D-\underline{F}_{j}\right) \gamma \underline{\theta}}{2}\right)\right\} \\
+(1-\nu)\left\{\rho\left[U\left(\bar{F}_{j}\right)+U\left(\left(D-\bar{F}_{j}\right)(\alpha+(1-\alpha) R \bar{\theta})+\alpha \bar{T}_{j}\right)\right]+(1-\rho) \cdot 2 \cdot U\left(\frac{\bar{F}_{j}+\left(D-\bar{F}_{j}\right) \gamma \bar{\theta}}{2}\right)\right\} .
\end{gathered}
$$

The expected welfare of the public authority in Country $j$ contracting with two banks is given by:

$$
\begin{gathered}
\nu\left\{\rho\left[U\left(\underline{F}_{j}\right)+U\left(\left(D-\underline{F}_{j}\right)(\alpha+(1-\alpha) R \underline{\theta})+2 \alpha \underline{\underline{T}}_{j}\right)\right]+(1-\rho) \cdot 2 \cdot U\left(\frac{\underline{F}_{j}+\left(D-\underline{F}_{j}\right) \gamma \underline{\theta}}{2}\right)\right\} \\
+(1-\nu)\left\{\rho\left[U\left(\bar{F}_{j}\right)+U\left(\left(D-\bar{F}_{j}\right)(\alpha+(1-\alpha) R \bar{\theta})+2 \alpha \bar{T}_{j}\right)\right]+(1-\rho) \cdot 2 \cdot U\left(\frac{\bar{F}_{j}+\left(D-\bar{F}_{j}\right) \gamma \bar{\theta}}{2}\right)\right\} .
\end{gathered}
$$

The difference with the expressions of welfare presented in previous sections comes from the rate of return of the risky investment which is now $\alpha+(1-\alpha) R \theta>1$ instead of 1 . In addition, taxes are multiplied by $\alpha$ since they are (partly) substitutes with the rate of return for the contestable deposits, as shown in equation (18). This is the crucial difference with the core of our analysis: households have now an interest in the risky investment through the competition between banks. This reduces the power of 
taxation as a regulatory instrument: the tax instrument is less effective in regulating the profits of banks. Therefore it becomes more difficult to use taxes so as to screen banks according to their efficiency levels. Taxes are also less welfare-enhancing since their redistributive function is only for a fraction of deposits. In the limit case of perfect competition on returns where $\alpha$ goes to zero, taxes completely lose their function as a regulatory instrument since representative households receive directly all gains from risky investment and banks of any type make zero profits. This implies that only a regulation on one instrument (liquidity requirements) is possible in such a case. In the empirical literature, spatial models of consumer demand for retail bank deposits that explicitly account for consumer disutility from distance traveled find significant market power for banks (see Ho and Ishii (2011)). ${ }^{29}$

Redoing our analysis with the new welfare functions when $0<\alpha<1$ leads to the following results, in which the various components of the Nash equilibrium are indexed with a superscript $e$.

Proposition 5 Under financial integration when banks compete for a fraction of deposits $\alpha \in(0,1)$, the unique Nash Equilibrium of the regulatory game

$$
\left(\bar{F}_{1}^{e}, \bar{T}_{1}^{e}, \underline{F}_{1}^{e}, \underline{T}_{1}^{e}, \bar{F}_{2}^{e}, \bar{T}_{2}^{e}, \underline{F}_{2}^{e}, \underline{T}_{2}^{e}, n_{1}^{e}, n_{2}^{e}\right)
$$

is a simple pooling contract where

(i) taxes are null for all types of banks in the two countries: $T^{e}:=\underline{T}_{j}^{e}=\bar{T}_{j}^{e}=0$, for all $j$

(ii) both the inefficient and efficient bank face the same liquidity regulation $F^{e}:=\bar{F}_{j}^{e}=$ $\underline{F}_{j}^{e}$, for all $j$, defined by

$$
\begin{aligned}
& \rho U^{\prime}\left(F^{e}\right)+(1-\rho)\left\{\nu(1-\gamma \underline{\theta}) U^{\prime}\left(\frac{F^{e}+\left(D-F^{e}\right) \gamma \underline{\theta}}{2}\right)\right. \\
& \left.\quad+(1-\nu)(1-\gamma \bar{\theta}) U^{\prime}\left(\frac{F^{e}+\left(D-F^{e}\right) \gamma \bar{\theta}}{2}\right)\right\} \\
& =\rho\left\{\nu(\alpha+(1-\alpha) R \underline{\theta}) U^{\prime}\left(\left(D-F^{e}\right)(\alpha+(1-\alpha) R \underline{\theta})\right)\right.
\end{aligned}
$$

\footnotetext{
${ }^{29}$ The existence of a competitive process between banks for deposits studied in this section amounts to assume that a bank may benefit from a partial monopoly position. This creates an incentive for banks to attract a customer basis in as many countries as possible and thus become multinational. But the decision of invest into an international banking network able to attract savers and collect savings is beyond the scope of the paper.
} 


$$
\left.+(1-\nu)(\alpha+(1-\alpha) R \bar{\theta}) U^{\prime}\left(\left(D-F^{e}\right)(\alpha+(1-\alpha) R \bar{\theta})\right)\right\}
$$

(iii) each country has one bank: $n^{e}:=n_{1}^{e}=n_{2}^{e}=1$;

(iv) all types of banks expect positive profits: $\bar{\Pi}_{j}^{e}>\underline{\Pi}_{j}^{e}>0$, for all $j$.

The qualitative properties of our main results do not change when competition for deposits is taken into account. In particular we still obtain a unique Nash equilibrium that exhibits no taxation: the competition between regulators leads to a pooling contract for the same reason as above, which is the loss of a regulatory instrument.

Yet the terms of a regulatory contract are modified since the rate of return on the risky asset and profits are modified. Since the representative household gets a share of profits from the contestable deposits even when taxes are equal to zero, she is interested in risk-taking activities by the bank. This affects the expected marginal cost associated to liquidity requirements (see the right hand side of equation (19)).

To sum up, competition between banks alters the way regulators compete and as a result it mitigates the redistributive losses from taxes on profits. At the same time the inability to properly screen banks in a financially integrated environment still remains present. Hence, as banks retain some market power, it does not modify our main conclusion: the mobility of banks severely hampers the capacity of regulators to use several instruments to regulate the banking industry. ${ }^{30}$

\section{Concluding remarks}

In this paper we study the incidence of regulatory arbitrage by banks in a financially integrated economy. We focus on the mobility of banks' activities as the sole link between regulators. The capacity of banks to de facto choose the regulatory contract according to which they operate means that national regulators face competition.

We show that an optimal regulatory contract is supported by two instruments: taxes on banks' profits and liquidity requirements. Even if a regulator is at an informational disadvantage with respect to banks, the optimal regulatory contract in the absence of bank mobility is designed to ensure that banks are regulated according to their efficiency characteristics. Given this benchmark result, our analysis reveals that the mobility of

\footnotetext{
${ }^{30} \mathrm{~A}$ similar setting could be used to address the case where the representative households can store cash. Supposing that at least a fraction $0<\alpha<1$ of their endowment must be deposited in her bank, the household would decide whether she wants to increase this amount. This case would result in a proposition exhibiting the same forces than the ones identified in Proposition 5.
} 
banks is a crucial determinant of the regulatory outcome in a multi-country economy. The competition between regulators that arises from regulatory arbitrage made by banks lead to the following result: one of the regulatory instrument (taxes) is eliminated and the regulators can no longer discriminate banks according to their characteristics. As a result banking regulation is characterized by a simple pooling contract with no tax and a unique liquidity requirement for all types of banks. In other words, financial integration drastically hampers the capacity of national regulators to mobilize the instruments adequate to regulate banks.

This pooling result is the theoretical counterpart to the criticism raised against the recent liquidity regulatory guidelines from the Basel Committee for Banking Supervision (BCBS). Kowalik (2013), surveying these guidelines, writes:

The new Basel provisions ... still determine liquidity buffer size and composition without taking into account the nature of an individual financial institution's risk profile, capital, and business activity ... One reason the BCBS opted not to pursue a more flexible, individualized approach is that such an approach would be hard to apply consistently across national borders and the comparability of liquidity positions among financial institutions would not be guaranteed.

Moreover Kowalik expresses the concern that :

The inflexible approach, however, raises concerns that some financial institutions may be required to hold buffers larger or smaller than necessary given the nature of their own operations. Moreover, an inflexible approach to determining buffer size and composition can invite "regulatory arbitrage." Financial institutions may devise strategies that exploit loopholes in the Basel provisions, undermining the integrity of the liquidity buffers.

Actually we prove that all banks benefit from the "inflexible approach", that is, the pooling equilibrium when the heterogeneity between banks' performances is not too high.

We then study how regulatory arbitrage can be dealt with. We show that allocating all regulatory capacities to an integrated regulator restores the capacity to discriminate among banks, that is, to efficiently regulate the risk-taking behavior of banks. Interestingly, the levels of risks undertaken by banks under competing regulators may be lower than under an integrated regulator. This shows that competition does not necessarily lead to a race to the bottom in regulatory standards and higher risk-taking by banks.

The integration of the financial system has spurred new forms of cooperation and coordination (see, e.g., Schooner and Taylor (2009) for a review). Our analysis suggests 
that practitioners trying to set up a more cooperative and common regulation of banks would tend to (re)introduce regulatory instruments that should affect the degree of the riskiness of banks' portfolio as well as instruments that regulate the overall profit of banks. Interestingly, in a recent proposal for the foundation of a banking union in Europe, the European Commission suggests the possibility of a new regulation of bank overall profit (close to a tax on profits) on top of the standard instrument, capital regulation (see Draft Proposal for a Council implementing regulation supplementing Regulation No 806/2014). Whether the current regulatory policies designed under the guidance of international standard-setting bodies reflect a cooperative or non-cooperative outcome and correspond to an efficient pattern of regulation is open to debate.

\section{References}

Acharya, V. V., 2003. Is the international convergence of capital adequacy regulation desirable? Journal of Finance, 58(6), 2745-2782.

Admati, A. and M.F. Hellwig, 2014. The Bankers' New Clothes: What's Wrong with Banking and What to Do about It. Princeton University Press.

Admati, A., DeMarzo, P.M., Hellwig, M.F. and P. Pfleiderer, 2011. Fallacies, Irrelevant Facts, and Myths in the Discussion of Capital Regulation: Why Bank Equity is Not Socially Expensive. Max Planck Working Paper.

Aiyar, S., Calomiris, C.W. and T. Wieladek, 2014. Does Macro-Prudential Regulation Leak? Evidence from a UK Policy Experiment. Journal of Money, Credit and Banking 46(1), 181-214.

Agarwal, S., Lucca, D., Seru, A. and F. Trebbi, 2014. Inconsistent regulators: Evidence from banking. Quarterly Journal of Economics, 889-938.

Allen, F. and D. Gale, 2004. Financial intermediaries and markets. Econometrica, 72(4), 1023-1061.

Armstrong, M. and J.-C. Rochet, 1999. Multi-dimensional screening: A user's guide. European Economic Review, 43(4), 959-979.

Armstrong, M. and J. Vickers, 2001. Competitive Price Discrimination. RAND Journal of Economics, 32(4), 579-605.

Attar, A., Mariotti, T. and F. Salanié, 2014. Multiple Contracting in Insurance Markets. TSE Working Paper. 
Barth, J.R., Caprio, G. and R. Levine, 2006. Rethinking Bank Regulation. Cambridge University Press.

Benoit, S., Colliard, J.-E., Hurlin, C. and C. Perignon, 2017. Where the Risks Lie: A Survey on Systemic Risk. Review of Finance, 21(1), 109-152.

Bierbrauer, F.J., Brett, C. and J.A. Weymark, 2013. Strategic nonlinear income tax competition with perfect labor mobility. Games and Economic Behavior, 82, 292-311.

Bierbrauer, F.J. and P.C. Boyer, 2016. Efficiency, Welare, and Political Competition. Quarterly Journal of Economics, 131(1), 461-518.

Bolton, P. and M. Dewatripont, 2004. Contract theory. Cambridge, MA: MIT Press.

Bolton, P., Santos, T. and J.A. Scheinkman, 2011. Outside and Inside Liquidity. Quarterly Journal of Economics 126.1: 259-321.

Bolton, P. and X. Freixas, 2006. Corporate finance and the monetary transmission mechanism. Review of Financial Studies, 19(3), 829-870.

Boyer, P.C. and J. Ponce, 2012. Regulatory capture and banking supervision reform. Journal of Financial Stability, 8, 206-217.

Carbo-Valverde, S., Kane, E.J. and F. Rodriguez-Fernandez, 2012. Regulatory Arbitrage in Cross-Border Banking Mergers within the EU. Journal of Money, Credit and Banking, 44(8), 1609-1629.

Carruthers, B.G. and N.R. Lamoreaux, 2016. Regulatory Races: The Effects of Jurisdictional Competition on Regulatory Standards. Journal of Economic Literature, 54(1), $52-97$.

Claessens, S., Keen, M., and C. Pazarbasioglu (Eds.), 2010. Financial sector taxation: The IMF's report to the G-20 and background material. Washington: International Monetary Fund.

Cochrane, J.H., 2014. Toward a run-free financial system. In Martin Neil Baily, John B. Taylor, eds., Across the Great Divide: New Perspectives on the Financial Crisis, Hoover Press.

Dell'Ariccia, G. and R. Marquez, 2006. Competition among regulators and credit market integration. Journal of Financial Economics, 79(2), 401-430. 
De Larosière, J., Balcerowicz, L., Issing, O., Masera, R., McCarthy, C., Nyberg, L., Pérez, J. and O. Ruding, 2009. The High-level Group on Financial Supervision in the EU. Brussels.

de Mooij, R. and G. Nicodème (Eds.), 2014. Taxation and Regulation of the Financial Sector. MIT Press.

Dewatripont, M. and J. Tirole, 1994. The prudential regulation of banks. MIT Press.

Dong, H., Song, F.M and L. Tao, 2011. Regulatory arbitrage: evidence from bank cross-border M\&As. Working paper, University of Hong Kong.

Engineer, M.H., Schure, P. and M. Gillis, 2013. A positive analysis of deposit insurance provision: Regulatory competition among European Union countries. Journal of Financial Stability, 9(4), 530-544.

Freixas, X. and J.-C. Rochet, 2008. Microeconomics of Banking, Second Edition. Cambridge, MA: MIT Press.

Freixas, X. and J.-C. Rochet, 2013. Taming systemically important financial institutions. Journal of Money, Credit, and Banking, 45(1), 37-58.

Giammarino, R.M., Lewis, T.R., and D.E. Sappington, 1993. An incentive approach to banking regulation. Journal of Finance, 48(4), 1523-15428.

Haufler, A. and U. Maier, 2016. Regulatory competition in capital standards with selection effects among banks. CESifo Working paper No. 5839.

Hart, O. and L. Zingales, 2011. A New Capital Regulation for Large Financial Institutions. American Law and Economics Review, 13, 453-490.

Ho, K. and J. Ishii, 2011. Location and competition in retail banking. International Journal of Industrial Organization, 29(5), 537-546.

Houston, J.F, Lin, C. and Y. Ma, 2012. Regulatory Arbitrage and International Bank Flows. Journal of Finance 67(5): 1845-1895.

Karolyi, G.A, and A.G. Taboada, 2015. Regulatory arbitrage and cross-border bank acquisitions. Journal of Finance 70(6): 2395-2449.

Keen, M. and K.A. Konrad, 2013. The theory of international tax competition and coordination. In Auerbach, A. J., Chetty, R., Feldstein, M., \& Saez, E. (eds.). Handbook of Public Economics (Vol. 5). 
Kowalik, M. (2013). Basel liquidity regulation: was it improved with the 2013 revisions? Economic Review-Federal Reserve Bank of Kansas City, 65.

Laffont, J.-J. and D. Martimort, 2002. The theory of incentives: The principal-agent model. Princeton University Press.

Laffont, J-J. and J. Tirole, 1993. A Theory of Incentives in Procurement and Regulation. Cambridge, MA: MIT Press.

Lehmann, E., Simula, L. and A. Trannoy, 2014. Tax Me If You Can! Optimal Nonlinear Income Tax between Competing Governments. Quarterly Journal of Economics, 129(4), 1995-2030.

Martimort, D., 2006. Multi-Contracting Mechanism Design. In Advances in Economics and Econometrics. R. Blundell, W. Newey and T. Persson (eds), 1, 56 -101.

Masciandaro, D. and M. Quintyn, 2016. The governance of financial supervision: recent developments. Journal of Economic Surveys, 30(5), 982-1006.

Miles, D., Yang, J. and G. Marcheggiano, 2013. Optimal Bank Capital. Economic Journal, 123(567), 1-37.

Morrison, A.D. and L. White, 2009. Level playing fields in international financial regulation. Journal of Finance, 64(3), 1099-1142.

Morelli, M., Yang, H. and L. Ye, 2012. Competitive nonlinear taxation and constitutional choice. American Economic Journal: Microeconomics, 4(1), 142-175.

Ongena, S., Popova, A. and G.F. Udell, 2013. When the cat's away the mice will play: Does regulation at home affect bank risk-taking abroad? Journal of Financial Economics 108 (3): 727-750.

Rochet J.-C., 2010. Systemic risk: changing the regulatory perspective. International Journal of Central Banking, 6:259-276.

Rochet J.-C. and L.A. Stole, 2002. Nonlinear Pricing with Random Participation. Review of Economic Studies, 69 (1), 277-311.

Rochet J.-C. and L.A. Stole, 2003. The Economics of Multidimensional Screening. In: Mathias Dewatripont et al. (eds.) Advances in Economics and Econometrics. 150-197. Cambridge: Cambridge University Press. 
Reinhardt, D. and R. Sowerbutts, 2015. Regulatory arbitrage in action: evidence from banking flows and macroprudential policy. Bank of England Staff Working paper no 546 .

Schepens, G., 2016. Taxes and bank capital structure. Journal of Financial Economics 120 (3): 585-600.

Schooner, H.M., and M.W. Taylor, 2009. Global bank regulation: principles and policies. Academic Press.

Shleifer, A., 1985. A theory of yardstick competition. RAND Journal of Economics 16 (3), 319-327.

Vives, X., 2001. Competition in the changing world of banking. Oxford Review of Economic Policy, 17(4), 535-547.

White, L.J., 1994. On the international harmonization of bank regulation. Oxford Review of Economic Policy, 94-105.

\section{Appendix}

\section{A Proofs}

\section{A.1 Proof of Proposition 1}

Step A. Following the standard treatment of the principal's problem under asymmetric information, we show that only the downward incentive compatibility constraint (4) ensuring that an efficient bank $\bar{\theta}$ is not willing to mimic an inefficient bank $\underline{\theta}$, and the inefficient bank's participation constraint (3) have to be considered when the monotonicity $\underline{F}>\bar{F}$ condition holds, which is Part (i) of Proposition 1.

We first show that equation (2) is satisfied as soon as (4) holds. This implication directly follows from rewriting (4) as

$$
\Pi(\bar{\theta}, \bar{\theta}) \geq \Pi(\underline{\theta}, \underline{\theta})+\rho R(\bar{\theta}-\underline{\theta})(D-\underline{F}) \geq 0 .
$$

We now show that the incentive compatibility constraint (5) is satisfied as soon as the monotonicity condition $\underline{F}>\bar{F}$ holds. We can write (5) as

$$
\Pi(\underline{\theta}, \underline{\theta}) \geq \Pi(\bar{\theta}, \bar{\theta})-\rho(D-\bar{F}) R(\bar{\theta}-\underline{\theta}) .
$$

If the incentive compatibility constraint (4) and the participation constraint (3) are binding at the optimum, then

$$
\Pi(\bar{\theta}, \bar{\theta})=\rho(D-\underline{F}) R(\bar{\theta}-\underline{\theta}),
$$


and (5) is not binding as soon as the monotonicity condition $\bar{F}<\underline{F}$ holds.

Since the incentive compatibility constraint (4) and the participation constraint (3) are binding at the optimum, we have that $\underline{T}=(D-\underline{F})(R \underline{\theta}-1)$, from (3) and from (4) we get

$$
\bar{T}=(D-\bar{F})(R \bar{\theta}-1)-R(\bar{\theta}-\underline{\theta})(D-\underline{F}) .
$$

Substituting these expressions in $\mathcal{W}^{1}$, the optimization problem of the authority is solved for $(\underline{F}, \bar{F})$ such that FOCs can be written as equations (10) and (11).

Step B. We now prove Parts (i) to (iii) of Proposition 1. Part (iv) directly follows from the symmetry of the two countries.

Proof of Part (i). By contradiction, suppose that $\bar{F}^{S} \geq \underline{F}^{S}$.

First, we prove that if $\bar{F}^{S} \geq \underline{F}^{S}$ then $\bar{T}^{S} \leq \underline{T}^{S}$.

We know that

$$
\begin{gathered}
\bar{T}^{S}-\underline{T}^{S}=\left(D-\bar{F}^{S}\right)(R \bar{\theta}-1)-R(\bar{\theta}-\underline{\theta})\left(D-\underline{F}^{S}\right)-\left(D-\underline{F}^{S}\right)(R \underline{\theta}-1) \\
=\left(\underline{F}^{S}-\bar{F}^{S}\right)(R \bar{\theta}-1)
\end{gathered}
$$

Therefore if $\bar{F}^{S} \geq \underline{F}^{S}$ then $\bar{T}^{S} \leq \underline{T}^{S}$.

Next, we prove that $D-\bar{F}^{\bar{S}}+\bar{T}^{S} \leq D-\underline{F}^{S}+\underline{T}^{S}$ if $\bar{F}^{S} \geq \underline{F}^{S}$. We have that

$$
D-\underline{F}^{S}+\underline{T}^{S}=\left(D-\underline{F}^{S}\right)(1+R \underline{\theta}-1)=\left(D-\underline{F}^{S}\right) R \underline{\theta}
$$

and

$$
\begin{gathered}
D-\bar{F}^{S}+\bar{T}^{S}=\left(D-\bar{F}^{S}\right) R \bar{\theta}-R(\bar{\theta}-\underline{\theta})\left(D-\underline{F}^{S}\right) \\
=\left(D-\underline{F}^{S}\right) R \underline{\theta}+R \bar{\theta}\left(\underline{F}^{S}-\bar{F}^{S}\right)=D-\underline{F}^{S}+\underline{T}^{S}+R \bar{\theta}\left(\underline{F}^{S}-\bar{F}^{S}\right) .
\end{gathered}
$$

Hence $D-\bar{F}^{S}+\bar{T}^{S} \leq D-\underline{F}^{S}+\underline{T}^{S}$ if $\bar{F}^{S} \geq \underline{F}^{S}$.

Now we use the FOCs given by (10) and (11):

$$
\begin{gathered}
\rho U^{\prime}\left(\underline{F}^{S}\right)+(1-\rho)(1-\gamma \underline{\theta}) U^{\prime}\left(\frac{\underline{F}^{S}+\left(D-\underline{F}^{S}\right) \gamma \underline{\theta}}{2}\right) \\
=\rho R \underline{\theta} U^{\prime}\left(D-\underline{F}^{S}+\underline{T}^{S}\right)-\frac{1-\nu}{\nu} \rho R(\bar{\theta}-\underline{\theta}) U^{\prime}\left(D-\bar{F}^{S}+\bar{T}^{S}\right),
\end{gathered}
$$

and

$$
\rho U^{\prime}\left(\bar{F}^{S}\right)+(1-\rho)(1-\gamma \bar{\theta}) U^{\prime}\left(\frac{\bar{F}^{S}+\left(D-\bar{F}^{S}\right) \gamma \bar{\theta}}{2}\right)=\rho R \bar{\theta} U^{\prime}\left(D-\bar{F}^{S}+\bar{T}^{S}\right),
$$

We can rewrite (20) as:

$$
\rho U^{\prime}\left(\underline{F}^{S}\right)+(1-\rho)(1-\gamma \underline{\theta}) U^{\prime}\left(\frac{\underline{F}^{S}+\left(D-\underline{F}^{S}\right) \gamma \underline{\theta}}{2}\right)
$$


$=\rho R \bar{\theta} U^{\prime}\left(D-\bar{F}^{S}+\bar{T}^{S}\right)+\rho R \underline{\theta}\left(U^{\prime}\left(D-\underline{F}^{S}+\underline{T}^{S}\right)-U^{\prime}\left(D-\bar{F}^{S}+\bar{T}^{S}\right)\right)-\frac{1}{\nu} \rho R(\bar{\theta}-\underline{\theta}) U^{\prime}\left(D-\bar{F}^{S}+\bar{T}^{S}\right)$.

The last two terms in the RHS of this equation are negative if $\bar{F}^{S} \geq \underline{F}^{S}$. Therefore the LHS of (20) is lower than the LHS of (21) if $\bar{F}^{S} \geq \underline{F}^{S}$.

This implies that

$\rho U^{\prime}\left(\underline{F}^{S}\right)+(1-\rho)(1-\gamma \underline{\theta}) U^{\prime}\left(\frac{\underline{F}^{S}+\left(D-\underline{F}^{S}\right) \gamma \underline{\theta}}{2}\right)<\rho U^{\prime}\left(\bar{F}^{S}\right)+(1-\rho)(1-\gamma \bar{\theta}) U^{\prime}\left(\frac{\bar{F}^{S}+\left(D-\bar{F}^{S}\right) \gamma \bar{\theta}}{2}\right)$,

equivalent to

$(1-\gamma \underline{\theta}) U^{\prime}\left(\frac{\underline{F}^{S}+\left(D-\underline{F}^{S}\right) \gamma \underline{\theta}}{2}\right)-(1-\gamma \bar{\theta}) U^{\prime}\left(\frac{\bar{F}^{S}+\left(D-\bar{F}^{S}\right) \gamma \bar{\theta}}{2}\right)<\frac{\rho}{1-\rho}\left[U^{\prime}\left(\bar{F}^{S}\right)-U^{\prime}\left(\underline{F}^{S}\right)\right]$,

which is impossible since $U^{\prime}\left(\bar{F}^{S}\right)-U^{\prime}\left(\underline{F}^{S}\right) \leq 0$ when $\bar{F}^{S} \geq \underline{F}^{S}$ but

$$
\begin{aligned}
& (1-\gamma \underline{\theta}) U^{\prime}\left(\frac{\underline{F}^{S}+\left(D-\underline{F}^{S}\right) \gamma \underline{\theta}}{2}\right)-(1-\gamma \bar{\theta}) U^{\prime}\left(\frac{\bar{F}^{S}+\left(D-\bar{F}^{S}\right) \gamma \bar{\theta}}{2}\right)> \\
& (1-\gamma \bar{\theta})\left(U^{\prime}\left(\frac{\underline{F}^{S}+\left(D-\underline{F}^{S}\right) \gamma \underline{\theta}}{2}\right)-U^{\prime}\left(\frac{\bar{F}^{S}+\left(D-\bar{F}^{S}\right) \gamma \bar{\theta}}{2}\right)\right)>0,
\end{aligned}
$$

since $\underline{F}^{S}(1-\gamma \underline{\theta})<\bar{F}^{S}(1-\gamma \underline{\theta})+\left(D-\bar{F}^{S}\right)(\bar{\theta}-\underline{\theta}) \gamma$ when $\bar{F}^{S} \geq \underline{F}^{S}$.

Hence, the variables $\underline{F}^{S}$ and $\bar{F}^{S}$, defined in equations (10) and (11) respectively, are such that $\underline{F}^{S}>\bar{F}^{S}$. This property is also the monotonicity condition so that (5) and (2) are satisfied.

Proof of Parts (ii) and (iii). Part (ii) of Proposition 1 directly follows from $\underline{F}^{S}>\bar{F}^{S}$ and equations (3) and (4). Indeed, $\bar{T}^{S}>\underline{T}^{S}$ since

$$
\bar{T}^{S}=\left(D-\bar{F}^{S}\right)(R \bar{\theta}-1)-R(\bar{\theta}-\underline{\theta})\left(D-\underline{F}^{S}\right)>\left(D-\underline{F}^{S}\right)(R \bar{\theta}-1)-R(\bar{\theta}-\underline{\theta})\left(D-\underline{F}^{S}\right),
$$

from $\underline{F}>\bar{F}$ and $\left(D-\underline{F}^{S}\right)(R \bar{\theta}-1)-R(\bar{\theta}-\underline{\theta})\left(D-\underline{F}^{S}\right)=\left(D-\underline{F}^{S}\right)[R \bar{\theta}-1-R \bar{\theta}+R \underline{\theta}]=\underline{T}^{S}$.

The profit of low efficient bank directly follows from equation (3). The profit of high efficient bank directly follows from equations (3) and (4).

\section{A.2 Proofs of Theorem 1 and Corollary 1}

The proofs of Theorem 1 and Corollary 1 follow two steps.

Step A: Symmetric location. If there exists a Nash equilibrium, we first show that it entails $n_{1}^{N}=n_{2}^{N}=1$.

From the location rule given by equation (6) there are three possible cases:

1. Symmetric case: $n_{1}=n_{2}=1$.

2. Asymmetric cases: $n_{1}=2$ and $n_{2}=0$ or $n_{1}=0$ and $n_{2}=2$. 
We show that the asymmetric cases cannot be supported as equilibria.

Suppose that there exists an equilibrium with $n_{1}=2$ and $n_{2}=0$. In such a case $P_{2}$ has a profitable deviation: if $P_{2}$ decides to offer the same contract as $P_{1}$, according to the location rule, it will obtain one bank and thus increase its tax receipts, while keeping the same share of liquid assets. Thus the welfare of its residents will increase so that the exclusion case cannot be an equilibrium. Hence, any equilibrium entails symmetric location of banks.

Step B: Equilibrium contracts. We show that, if there exists a Nash equilibrium it is unique and it involves, for all $j, T^{N}:=\underline{T}_{j}^{N}=\bar{T}_{j}^{N}=0$ and $F^{N}:=\underline{F}_{j}^{N}=\bar{F}_{j}^{N}$ given by equation (14).

Part 1: We show that in any Nash equilibrium $T^{N}:=\underline{T}_{j}^{N}=\bar{T}_{j}^{N}=0$ for all $j$. Suppose that there is a Nash equilibrium with $\underline{\hat{F}}:=\underline{F}_{1}=\underline{F}_{2}, \hat{\bar{F}}:=\bar{F}_{1}=\bar{F}_{2}, \underline{\hat{T}}:=\underline{T}_{1}=\underline{T}_{2}$, and $\hat{\bar{T}}:=\bar{T}_{1}=\bar{T}_{2}$.

If $\underline{\hat{T}} \neq 0$, we show that there exists a profitable deviation for $P_{j}$ involving $\underline{\tilde{T}}=\underline{\hat{T}}-\varepsilon$, with $\varepsilon>0$, while keeping $\underline{\hat{F}}, \hat{\bar{F}}$, and $\hat{\bar{T}}$, for any $\underline{\hat{F}}, \hat{\bar{F}}$, and $\hat{\bar{T}}$.

Since $\underline{\tilde{T}}=\underline{\hat{T}}-\varepsilon$ and $\underline{\hat{F}}$ identical, the deviation increases the bank profits of type $\underline{\theta}$ with respect to the other contract $-j$. From the location rule, such deviation attracts all banks $\underline{\theta}$ and then $n_{j}=2$ when banks have a low type. The expected welfare of $P_{j}$ following this deviation is

$$
\begin{aligned}
\nu\left\{\rho[U(\underline{\hat{F}})+U(D-\underline{\hat{F}}+2 \underline{\hat{T}}-2 \varepsilon)]+(1-\rho) \cdot 2 \cdot U\left(\frac{\underline{\hat{F}}+(D-\underline{\hat{F}}) \gamma \underline{\theta}}{2}\right)\right\} \\
+(1-\nu)\left\{\rho[U(\hat{\bar{F}})+U(D-\hat{\bar{F}}+\hat{\bar{T}})]+(1-\rho) \cdot 2 \cdot U\left(\frac{\hat{\bar{F}}+(D-\hat{\bar{F}}) \gamma \bar{\theta}}{2}\right)\right\} .
\end{aligned}
$$

The difference in expected welfare from this deviation for $P_{j}$ is then

$$
\nu \rho[U(D-\underline{\hat{F}}+2 \underline{\hat{T}}-2 \varepsilon)-U(D-\underline{\hat{F}}+\underline{\hat{T}})],
$$

which is strictly positive if $\varepsilon$ is sufficiently close to 0 . Hence any contract with $\underline{\hat{T}} \neq 0$ cannot be part of a Nash equilibrium.

Similarly, if $\hat{\bar{T}} \neq 0$, there exists a profitable deviation involving $\tilde{\bar{T}}=\hat{\bar{T}}-\varepsilon$, with $\varepsilon>0$, while keeping $\underline{\hat{F}}$ and $\hat{\bar{F}}$, and $\underline{\hat{T}}$, for any $\underline{\hat{F}}$ and $\hat{\bar{F}}$, and $\underline{\hat{T}}$.

Remark on subsidies. In the main text, we claim that ruling out the possibility of subsidies is without loss of generality. This can be shown using the argument above: Suppose that there is a Nash equilibrium with $\underline{\hat{F}}:=\underline{F}_{1}=\underline{F}_{2}, \hat{\bar{F}}:=\bar{F}_{1}=\bar{F}_{2}, \underline{\hat{T}}:=\underline{T}_{1}=\underline{T}_{2}$, and $\hat{\bar{T}}:=\bar{T}_{1}=\bar{T}_{2}$. If $0>\underline{\hat{T}}$ then one can show that there exists a profitable deviation for $P_{j}$ involving $\underline{\underline{T}}=\underline{\hat{T}}+\varepsilon$, with $\varepsilon>0$, while keeping $\underline{\hat{F}}, \hat{\bar{F}}$, and $\hat{\bar{T}}$, for any $\underline{\hat{F}}, \hat{\bar{F}}$, and $\hat{\bar{T}}$. Intuitively, this leads to a situation in 
which the liquidity requirements are identical and less rent is left to the banks. This argument eliminates the existence of subsidies in equilibrium in our setup.

Part 2: We show that $F^{N}:=\underline{F}_{j}^{N}=\bar{F}_{j}^{N}$, for all $j$, given by equation (14). Since taxes are null in any equilibrium from Part 1 the two incentive compatibility constraints (4) and (5) are binding; this implies that $\underline{F}_{j}^{N}=\bar{F}_{j}^{N}$, for all $j$.

The optimization problem of the public authorities is then

$$
\begin{gathered}
\max _{F} \rho[U(F)+U(D-F)] \\
+2(1-\rho)\left\{\nu U\left(\frac{F+(D-F) \gamma \underline{\theta}}{2}\right)+(1-\nu) U\left(\frac{F+(D-F) \gamma \bar{\theta}}{2}\right)\right\} .
\end{gathered}
$$

It follows from the first order condition that the level of liquid assets $F^{N}$ is uniquely given by equation (14).

\section{A.3 Proof of Proposition 2}

The proof of Parts (i), (ii) and (iv) of Proposition 2 follows the same steps as the proof of Proposition 1. Part (iii) of Proposition 2 follows the location rule: banks are offered the same contract in the two countries and they would realize the same profit in the two countries. This implies that they remain in the country where they collect deposits.

\section{A.4 Proof of Proposition 3}

Proof of Part (i). From previous propositions, we know that $\bar{T}^{S}>\underline{T}^{S}>T^{N}=0$.

Proof of Part (ii). From previous propositions, we know that: $\bar{\Pi}^{N}>\underline{\Pi}^{N}>0$ and $\bar{\Pi}^{S}>$ $\underline{\Pi}^{S}=0$.

Given the definition of profits, dealing with the less efficient bank, we have:

$$
\underline{\Pi}^{N}-\underline{\Pi}^{S}=\underline{\Pi}^{N}>0 .
$$

The profit of the efficient bank, in the integrated contract is equal to:

$$
\bar{\Pi}^{S}=R(\bar{\theta}-\underline{\theta})\left(D-\underline{F}^{S}\right),
$$

and its profit in the pooling contract is equal to:

$$
\bar{\Pi}^{N}=(R \bar{\theta}-1)\left(D-F^{N}\right) .
$$

If $\Delta \theta$ is small we get that $\bar{\Pi}^{N}-\bar{\Pi}^{S}$ is positive. 
Proof of Part (iii). We now show that $F^{N}>\underline{F}^{S}$ when $\Delta \theta$ is small. The proof has three steps:

Step 1: Suppose that $\underline{\theta}=\bar{\theta}=\theta$, we know that $\underline{F}^{S}=\bar{F}^{S} \equiv \widetilde{F} \neq F^{N}$. Let us assume that $\widetilde{F} \geq F^{N}$. The difference between the FOCs of $F^{N}$ and $\widetilde{F}$ gives

$$
\begin{gathered}
\rho\left(U^{\prime}\left(F^{N}\right)-U^{\prime}(\widetilde{F})\right)+(1-\rho)(1-\gamma \theta)\left(U^{\prime}\left(\frac{F^{N}+\left(D-F^{N}\right) \gamma \theta}{2}\right)-U^{\prime}\left(\frac{\widetilde{F}+(D-\widetilde{F}) \gamma \theta}{2}\right)\right) \\
=\rho\left(U^{\prime}\left(D-F^{N}\right)-R \theta U^{\prime}(D-\widetilde{F}+\widetilde{T})\right) \\
=\rho\left(U^{\prime}\left(D-F^{N}\right)-U^{\prime}(D-\widetilde{F})+U^{\prime}(D-\widetilde{F})-R \theta U^{\prime}((D-\widetilde{F}) R \theta)\right) .
\end{gathered}
$$

If $\widetilde{F} \geq F^{N}$, the LHS is weakly positive and the RHS is negative under Assumption 1 which is impossible. Therefore $\widetilde{F}<F^{N}$.

Step 2: For $\underline{\theta} \neq \bar{\theta}$, the difference between the FOCs of $F^{N}$ and $\underline{F}^{S}$ is

$$
\begin{gathered}
\rho\left(U^{\prime}\left(F^{N}\right)-\nu U^{\prime}\left(\underline{F}^{S}\right)\right)-\rho U^{\prime}\left(D-F^{N}\right)+\rho \nu R \underline{\theta} U^{\prime}\left(D-\underline{F}^{S}+\underline{T}^{S}\right) \\
+(1-\rho)\left\{\nu(1-\gamma \underline{\theta}) U^{\prime}\left(\frac{F^{N}+\left(D-F^{N}\right) \gamma \underline{\theta}}{2}\right)+(1-\nu)(1-\gamma \bar{\theta}) U^{\prime}\left(\frac{F^{N}+\left(D-F^{N}\right) \gamma \bar{\theta}}{2}\right)\right\} \\
-(1-\rho)(1-\gamma \underline{\theta}) \nu U^{\prime}\left(\frac{\underline{F}^{S}+\left(D-\underline{F}^{S}\right) \gamma \underline{\theta}}{2}\right)-(1-\nu) \rho R(\bar{\theta}-\underline{\theta}) U^{\prime}\left(D-\bar{F}^{S}+\bar{T}^{S}\right)=0 \\
\rho\left(U^{\prime}\left(F^{N}\right)-\nu U^{\prime}\left(\underline{F}^{S}\right)\right)-\rho\left(U^{\prime}\left(D-F^{N}\right)-\nu R \underline{\theta} U^{\prime}\left(D-\underline{F}^{S}+\underline{T}^{S}\right)\right) \\
+(1-\rho)(1-\gamma \underline{\theta}) \nu\left[U^{\prime}\left(\frac{F^{N}+\left(D-F^{N}\right) \gamma \underline{\theta}}{2}\right)-U^{\prime}\left(\frac{\underline{F}^{S}+\left(D-\underline{F^{S}}\right) \gamma \underline{\theta}}{2}\right)\right] \\
+(1-\nu)(1-\rho)(1-\gamma \bar{\theta}) U^{\prime}\left(\frac{F^{N}+\left(D-F^{N}\right) \gamma \bar{\theta}}{2}\right)-(1-\nu) \rho R(\bar{\theta}-\underline{\theta}) U^{\prime}\left(D-\bar{F}^{S}+\bar{T}^{S}\right)=0 .
\end{gathered}
$$

If $F^{N}=\underline{F}^{S},(23)$ can be expressed as:

$$
\begin{gathered}
\rho(1-\nu)\left[U^{\prime}\left(F^{N}\right)-R \bar{\theta} U^{\prime}\left(\left(D-F^{N}\right) R \bar{\theta}\right)\right] \\
+\rho(1-\nu)\left[R \bar{\theta} U^{\prime}\left(\left(D-F^{N}\right) R \bar{\theta}\right)-R \bar{\theta} U^{\prime}\left(\left(D-F^{N}\right) R \bar{\theta}-R(\bar{\theta}-\underline{\theta})\left(D-\underline{F}^{S}\right)\right)\right] \\
-(1-\nu) \rho R \underline{\theta}\left(U^{\prime}\left(\left(D-F^{N}\right) R \underline{\theta}\right)-U^{\prime}\left(D-\bar{F}^{S}+\bar{T}^{S}\right)\right)= \\
\rho\left(U^{\prime}\left(D-F^{N}\right)-R \underline{\theta} U^{\prime}\left(\left(D-F^{N}\right) R \underline{\theta}\right)\right) \\
-(1-\rho)(1-\nu)(1-\gamma \bar{\theta}) U^{\prime}\left(\frac{F^{N}+\left(D-F^{N}\right) \gamma \bar{\theta}}{2}\right),
\end{gathered}
$$

or equivalently:

$$
\begin{gathered}
\rho(1-\nu)\left[U^{\prime}\left(F^{N}\right)-U^{\prime}\left(D-F^{N}\right)\right]+\rho(1-\nu)\left[U^{\prime}\left(D-F^{N}\right)-R \bar{\theta} U^{\prime}\left(\left(D-F^{N}\right) R \bar{\theta}\right)\right] \\
+\rho(1-\nu)\left[R \bar{\theta} U^{\prime}\left(\left(D-F^{N}\right) R \bar{\theta}\right)-R \bar{\theta} U^{\prime}\left(\left(D-F^{N}\right) R \bar{\theta}-R(\bar{\theta}-\underline{\theta})\left(D-\underline{F}^{S}\right)\right)\right]
\end{gathered}
$$




$$
\begin{gathered}
-(1-\nu) \rho R \underline{\theta}\left(U^{\prime}\left(\left(D-F^{N}\right) R \underline{\theta}\right)-U^{\prime}\left(D-\bar{F}^{S}+\bar{T}^{S}\right)\right)= \\
\rho\left(U^{\prime}\left(D-F^{N}\right)-R \underline{\theta} U^{\prime}\left(\left(D-F^{N}\right) R \underline{\theta}\right)\right) \\
-(1-\rho)(1-\nu)(1-\gamma \bar{\theta}) U^{\prime}\left(\frac{F^{N}+\left(D-F^{N}\right) \gamma \bar{\theta}}{2}\right) \\
\Leftrightarrow \\
(1-\nu)\left[\rho\left(U^{\prime}\left(F^{N}\right)-U^{\prime}\left(D-F^{N}\right)\right)+(1-\rho)(1-\gamma \bar{\theta}) U^{\prime}\left(\frac{F^{N}+\left(D-F^{N}\right) \gamma \bar{\theta}}{2}\right)\right] \\
+\rho(1-\nu)\left[R \bar{\theta} U^{\prime}\left(\left(D-F^{N}\right) R \bar{\theta}\right)-R \bar{\theta} U^{\prime}\left(\left(D-F^{N}\right) R \bar{\theta}-R(\bar{\theta}-\underline{\theta})\left(D-\underline{F}^{S}\right)\right)\right] \\
-(1-\nu) \rho R \underline{\theta}\left(U^{\prime}\left(\left(D-F^{N}\right) R \underline{\theta}\right)-U^{\prime}\left(D-\bar{F}^{S}+\bar{T}^{S}\right)\right)= \\
\rho\left(U^{\prime}\left(D-F^{N}\right)-R \underline{\theta} U^{\prime}\left(\left(D-F^{N}\right) R \underline{\theta}\right)\right)-\rho(1-\nu)\left[U^{\prime}\left(D-F^{N}\right)-R \bar{\theta} U^{\prime}\left(\left(D-F^{N}\right) R \bar{\theta}\right)\right] .
\end{gathered}
$$

Notice that from equation (14),

$$
\begin{gathered}
\rho\left(U^{\prime}\left(F^{N}\right)-U^{\prime}\left(D-F^{N}\right)\right)+(1-\rho)(1-\gamma \bar{\theta}) U^{\prime}\left(\frac{F^{N}+\left(D-F^{N}\right) \gamma \bar{\theta}}{2}\right) \\
=\nu(1-\rho)\left[(1-\gamma \bar{\theta}) U^{\prime}\left(\frac{F^{N}+\left(D-F^{N}\right) \gamma \bar{\theta}}{2}\right)-(1-\gamma \underline{\theta}) U^{\prime}\left(\frac{F^{N}+\left(D-F^{N}\right) \gamma \underline{\theta}}{2}\right)\right] .
\end{gathered}
$$

Hence, when $\Delta \theta=\bar{\theta}-\underline{\theta}$ goes to 0 , the LHS of equation (24) tends toward 0 whereas the RHS tends toward:

$$
\rho \nu\left[U^{\prime}\left(D-F^{N}\right)-R \underline{\theta} U^{\prime}\left(\left(D-F^{N}\right) R \underline{\theta}\right)\right],
$$

which is negative under Assumption 1. Hence, for a small enough $\Delta \theta$, it is impossible that $F^{N}=\underline{F}^{S}$.

Step 3: From the continuity properties of the functions we study, the two results from Step 1 and Step 2 imply that for any couple $(\underline{\theta}, \bar{\theta})$, and a difference $\Delta \theta$ small enough $F^{N}>\underline{F}^{S}$. Finally, from Proposition 1, we get:

$$
F^{N}>\underline{F}^{S}>\bar{F}^{S}
$$

if $\Delta \theta$ is small enough.

\section{A.5 Proof Proposition 4}

We omit the proof of Proposition 4 since it follows the one of Theorem 1 and Corollary 1.

\section{A.6 Proof Proposition 5}

We omit the proof of Proposition 5 since it follows the one of Theorem 1 and Corollary 1.

\section{B Existence of Nash Equilibria}

In this section we prove the existence of Nash equilibria. 


\section{B.1 Necessary and sufficient condition}

The following Proposition provides a necessary and sufficient condition under incomplete information for the existence of a Nash equilibrium in pure strategies.

Proposition B.1 A Nash equilibrium exists if and only if there is no profitable deviation in the set of admissible contracts for regulator $P_{j}$, for all $j$.

Since we have a characterization of the unique equilibrium in terms of the primitives of the model, Proposition B.1 tells us that equilibrium existence can be checked by investigating whether there is a best-response to our equilibrium that generates a welfare gain. We use the result in Proposition B.1 to derive conditions for the existence of a pure strategy equilibrium.

\section{B.2 Sufficiency condition}

From Theorem 1, the welfare obtained in our equilibrium which we denote by $\mathcal{W}^{N}$ is given by:

$$
\begin{gathered}
\mathcal{W}^{N}=\rho\left[U\left(F^{N}\right)+U\left(D-F^{N}\right)\right] \\
+2(1-\rho)\left\{\nu U\left(\frac{F^{N}+\left(D-F^{N}\right) \gamma \underline{\theta}}{2}\right)+(1-\nu) U\left(\frac{F^{N}+\left(D-F^{N}\right) \gamma \bar{\theta}}{2}\right)\right\} .
\end{gathered}
$$

In order to derive a sufficient condition for existence we have to consider the four possible following deviations:

(a) Deviation with a pooling contract.

(b) Deviation with a separating contract attracting $\underline{\theta}$-banks only.

(c) Deviation with a separating contract attracting $\bar{\theta}$-banks only.

(d) Deviation with a separating contract attracting $\underline{\theta}$ and $\bar{\theta}$ banks.

(a): A deviation with a pooling contract means that the same contract is offered to banks irrespective of their type. A profitable deviation with a pooling contract requires that

$$
\tilde{\Pi}(\underline{\theta})=(D-\tilde{F})(R \underline{\theta}-1)-\tilde{T} \geq\left(D-F^{N}\right)(R \underline{\theta}-1),
$$

and

$$
\tilde{\Pi}(\bar{\theta})=(D-\tilde{F})(R \bar{\theta}-1)-\tilde{T} \geq\left(D-F^{N}\right)(R \bar{\theta}-1) .
$$

Since the authority's welfare maximization leads to a minimization of the profit of the banks, $\tilde{T}$ is as high as possible hence

$$
\tilde{T}=\left(F^{N}-\tilde{F}\right)(R \underline{\theta}-1) .
$$

Then the deviation must be such that both types of banks want to move to the deviating authority.

The welfare obtained from this deviation is

$$
\begin{gathered}
\tilde{\mathcal{W}}=\rho[U(\tilde{F})+U(D-\tilde{F}+2 \tilde{T})] \\
+2(1-\rho)\left\{\nu U\left(\frac{\tilde{F}+(D-\tilde{F}) \gamma \underline{\theta}}{2}\right)+(1-\nu) U\left(\frac{\tilde{F}+(D-\tilde{F}) \gamma \bar{\theta}}{2}\right)\right\} .
\end{gathered}
$$


The welfare from this deviation is lower than the one $\tilde{\mathcal{W}}$ in (c) when $R \underline{\theta} \approx 1$. Indeed $F^{S}>\tilde{F}^{S}$, $\tilde{\bar{T}}>\tilde{T}^{S}$ when $\tilde{F}^{S}=\tilde{\bar{F}}$ so that any profitable deviation done in (a) can be replicated by a deviation done in (c) below whereas the contrary is not true. Hence, showing that there is no profitable in (c) is sufficient.

(b): A profitable deviation attracting $\underline{\theta}$-banks is a contract $(\underline{\tilde{F}}, \underline{\tilde{T}})$ offered to all banks such that only $\underline{\theta}$-banks are attracted, that is:

$$
\underline{\tilde{\Pi}}(\underline{\theta})=(D-\underline{\tilde{F}})(R \underline{\theta}-1)-\underline{\tilde{T}} \geq \Pi^{N}(\underline{\theta})=\left(D-F^{N}\right)(R \underline{\theta}-1),
$$

leading to

$$
\underline{\tilde{T}}=\left(F^{N}-\underline{\tilde{F}}\right)(R \underline{\theta}-1)
$$

and

leading to

$$
\Pi^{N}(\bar{\theta})=\left(D-F^{N}\right)(R \bar{\theta}-1)>\underline{\tilde{\Pi}}(\bar{\theta})=(D-\underline{\tilde{F}})(R \bar{\theta}-1)-\underline{\tilde{T}},
$$

$$
\underline{\tilde{T}}>\left(F^{N}-\underline{\tilde{F}}\right)(R \bar{\theta}-1) .
$$

It is impossible to satisfy the two equations for the tax $\underline{\tilde{T}}$ simultaneously since a deviation attracting $\underline{\theta}$-banks also attracts $\bar{\theta}$-banks. We are then back to the case of a deviation with a pooling contract studied above in (a).

(c): A profitable deviation attracting $\underline{\theta}$-banks is a contract $(\tilde{\bar{F}}, \tilde{\bar{T}})$ offered to all banks but such that only $\bar{\theta}$-banks are attracted, that is:

$$
\Pi^{N}(\underline{\theta})=\left(D-F^{N}\right)(R \underline{\theta}-1)>\tilde{\bar{\Pi}}(\underline{\theta})=(D-\tilde{\bar{F}})(R \underline{\theta}-1)-\tilde{\bar{T}}
$$

and

$$
\tilde{\bar{\Pi}}(\bar{\theta})=(D-\tilde{\bar{F}})(R \bar{\theta}-1)-\tilde{\bar{T}} \geq \Pi^{N}(\bar{\theta})=\left(D-F^{N}\right)(R \bar{\theta}-1) .
$$

Since the authority's welfare maximization leads to a minimization of the profit of the banks, $\tilde{T}$ is as high as possible hence

$$
\tilde{\bar{T}}=\left(F^{N}-\tilde{\bar{F}}\right)(R \bar{\theta}-1),
$$

which implies only $\bar{\theta}$-banks wants to move to the deviating authority.

The expected welfare obtained from this deviation is

$$
\begin{aligned}
& \tilde{\tilde{\mathcal{W}}}=\nu\left\{\rho\left[U\left(F^{N}\right)+U\left(D-F^{N}\right)\right]+2(1-\rho) U\left(\frac{F^{N}+\left(D-F^{N}\right) \gamma \underline{\theta}}{2}\right)\right\} \\
& +(1-\nu)\left\{\rho[U(\tilde{\bar{F}})+U(D-\tilde{\bar{F}}+2 \tilde{\bar{T}})]+2(1-\rho) U\left(\frac{\tilde{\bar{F}}+(D-\tilde{\bar{F}}) \gamma \bar{\theta}}{2}\right)\right\} .
\end{aligned}
$$

Hence,

$$
\begin{gathered}
\tilde{\overline{\mathcal{W}}}-\mathcal{W}^{N}= \\
(1-\nu)\left\{\rho[U(\tilde{\bar{F}})+U(D-\tilde{\bar{F}}+2 \tilde{\bar{T}})]+2(1-\rho) U\left(\frac{\tilde{\bar{F}}+(D-\tilde{\bar{F}}) \gamma \bar{\theta}}{2}\right)\right.
\end{gathered}
$$




$$
\left.-\left\{\rho\left[U\left(F^{N}\right)+U\left(D-F^{N}\right)\right]+2(1-\rho) U\left(\frac{F^{N}+\left(D-F^{N}\right) \gamma \bar{\theta}}{2}\right)\right\}\right\} .
$$

Suppose that $R \bar{\theta}$ arbitrarily close to 1 then $\tilde{\mathcal{W}}-\mathcal{W}^{N}<0$. Hence, since

$$
\frac{d\left(\tilde{\overline{\mathcal{W}}}-\mathcal{W}^{N}\right)}{d R \bar{\theta}}=(1-\nu) \rho\left(F^{N}-\tilde{\bar{F}}\right) U^{\prime}(D-\tilde{\bar{F}}+2 \tilde{\bar{T}})
$$

is monotonically increasing in $R \bar{\theta}$ and from the monotonicity of $U(\cdot)$, there is a cutoff value of $R \bar{\theta}$ such that $\tilde{\mathcal{W}}-\mathcal{W}^{N}$ is positive. Hence, $R \bar{\theta}$ below this cutoff is a sufficient condition for existence.

(d): A profitable separating deviation is a contract $(\tilde{\bar{F}}, \tilde{\bar{T}}, \underline{\tilde{F}}, \underline{\tilde{T}})$ offered to all banks such that both $\bar{\theta}$-banks and $\underline{\theta}$-banks are attracted, that is:

$$
\begin{aligned}
& \underline{\tilde{\Pi}}(\underline{\theta})=(D-\underline{\tilde{F}})(R \underline{\theta}-1)-\underline{\tilde{T}} \geq \Pi^{N}(\underline{\theta})=\left(D-F^{N}\right)(R \underline{\theta}-1), \\
& \tilde{\bar{\Pi}}(\bar{\theta})=(D-\tilde{\bar{F}})(R \bar{\theta}-1)-\tilde{\bar{T}} \geq \Pi^{N}(\bar{\theta})=\left(D-F^{N}\right)(R \bar{\theta}-1),
\end{aligned}
$$

and the incentive compatibility constraint (4) is satisfied.

Since the authority's welfare maximization leads to a minimization of the profit of the banks, $\underline{\tilde{T}}$ and $\tilde{\bar{T}}$ are as high as possible hence

$$
\underline{\tilde{T}}=\left(F^{N}-\underline{\tilde{F}}\right)(R \underline{\theta}-1),
$$

and

$$
\tilde{\bar{T}}=\left(F^{N}-\tilde{\bar{F}}\right)(R \bar{\theta}-1) .
$$

From the incentive compatibility constraint (4), we have

$$
\tilde{\bar{\Pi}}(\bar{\theta})=(D-\tilde{\bar{F}})(R \bar{\theta}-1)-\tilde{\bar{T}} \geq(D-\underline{\tilde{F}})(R \bar{\theta}-1)-\underline{\tilde{T}} .
$$

We rewrite this constraint as

$$
\tilde{\bar{\Pi}}(\bar{\theta})=(D-\tilde{\bar{F}})(R \bar{\theta}-1)-\tilde{\bar{T}} \geq \underline{\tilde{\Pi}}(\bar{\theta})+(D-\underline{\tilde{F}}) R(\bar{\theta}-\underline{\theta}) .
$$

We can then substitute the expression of $\underline{\Pi}(\bar{\theta})$ and $\tilde{\bar{\Pi}}(\bar{\theta})$ with the taxes $(25)$ and $(26)$. This gives

$$
\begin{gathered}
\tilde{\bar{\Pi}}(\bar{\theta})=\left(D-F^{N}\right)(R \bar{\theta}-1) \geq\left(D-F^{N}\right)(R \underline{\theta}-1)+(D-\underline{\tilde{F}}) R(\bar{\theta}-\underline{\theta}) \Leftrightarrow \\
\left(D-F^{N}\right) R(\bar{\theta}-\underline{\theta}) \geq(D-\underline{\tilde{F}}) R(\bar{\theta}-\underline{\theta}) \Leftrightarrow \\
\underline{\tilde{F}} \geq F^{N}
\end{gathered}
$$

which contradicts the condition requiring that the tax is positive for low-type banks.

Notice that a deviation with the optimal second-best (separating) contracts under integrated regulation in Proposition 1 would not attract any banks since profits would be lower than the one in the Nash equilibrium for all types of banks, see Part (ii) of Proposition 3. 


\section{Optimal regulation without competing regulators: Com- plete information benchmark}

Under complete information and in the absence of regulatory arbitrage, as the regulator is able to observe the bank efficiency parameter in the economy, it can directly allocate banks to the regulatory scheme based on their type so that the incentive compatibility constraints can be ignored.

The problem of the regulator $j$ in this case is to maximize $\mathcal{W}_{j}^{1}$ given by (8), with respect to $\left(\underline{F}_{j}, \bar{F}_{j}, \underline{T}_{j}, \bar{T}_{j}\right)$ subject to $(2)$ and $(3)$.

Since the welfare of the authority is decreasing in the bank profit, ${ }^{31}$ the participation constraints of banks will be binding. Substituting the expression of the taxes in (8), the optimization problem of the authority is solved for $(\underline{F}, \bar{F})$.

We denote with a superscript $*$ the optimal regulatory contract in this configuration and we drop the subscript $j$ since we consider a single country.

Proposition C.1 The regulatory contract offered when a regulator does not compete for attracting banks to its jurisdiction under complete information is such that

(i) the less efficient bank faces more stringent liquidity requirement than the efficient one: $\underline{F}^{*}>$ $\bar{F}^{*}$, under Assumption 1, where

$$
\rho U^{\prime}\left(\underline{F}^{*}\right)+(1-\rho)(1-\gamma \underline{\theta}) U^{\prime}\left(\frac{\underline{F}^{*}+\left(D-\underline{F}^{*}\right) \gamma \underline{\theta}}{2}\right)=\rho R \underline{\theta} U^{\prime}\left(D-\underline{F}^{*}+\underline{T}^{*}\right),
$$

and

$$
\rho U^{\prime}\left(\bar{F}^{*}\right)+(1-\rho)(1-\gamma \bar{\theta}) U^{\prime}\left(\frac{\bar{F}^{*}+\left(D-\bar{F}^{*}\right) \gamma \bar{\theta}}{2}\right)=\rho R \bar{\theta} U^{\prime}\left(D-\bar{F}^{*}+\bar{T}\right)
$$

(ii) the less efficient bank faces a lower but positive tax level than the efficient one: $0<\underline{T}^{*}<\bar{T}^{*}$ where

$$
\underline{T}^{*}=\left(D-\underline{F}^{*}\right)(R \underline{\theta}-1)
$$

and

$$
\bar{T}^{*}=\left(D-\bar{F}^{*}\right)(R \bar{\theta}-1) ;
$$

(iii) all types of banks expect zero profits: $\bar{\Pi}^{*}=\underline{\Pi}^{*}=0$.

Proposition C.1 describes the properties of the optimal regulatory contracts when there are no informational frictions and banks cannot choose their regulator. In this environment, the efficient bank is allowed to take more risks than the inefficient one in order to exploit its ability

\footnotetext{
${ }^{31}$ This can be easily seen by substituting $\bar{T}=(D-\bar{F})(R \bar{\theta}-1)-\frac{1}{\rho} \Pi(\bar{\theta})$ and $\underline{T}=(D-\underline{F})(R \underline{\theta}-1)-\frac{1}{\rho} \Pi(\underline{\theta})$ in the objective of the public authority.
} 
to generate better returns from the risky assets. ${ }^{32}$ However, profits generated when no liquidation occurs by the two types of banks are fully taxed leaving the banks with zero profits. Since an efficient bank generates more profits than an inefficient one from the same investment and is allowed to take more risks, it will be subject to higher taxes in order to bring back its profits to zero.

\footnotetext{
${ }^{32}$ Notice that this ranking is valid under Assumption 1, which is not required to obtain the ranking under incomplete information. This is the natural case to consider under complete information.
} 